\title{
FAirness And Redistribution: US VERSUS EUROPE*
}

\author{
Alberto Alesina \\ Harvard University, IGIER, NBER \& CEPR
}

George-Marios Angeletos

MIT \& NBER

October 2002

\begin{abstract}
Different beliefs about how fair social competition is and what determines income inequality, influence the redistributive policy chosen democratically in a society. But the composition of income in the first place depends on equilibrium tax policies. If a society believes that individual effort determines income, and that all have a right to enjoy the fruits of their effort, it will chose low redistribution and low taxes. In equilibrium effort will be high, the role of luck limited, market outcomes will be quite fair, and social beliefs will be self-fulfilled. If instead a society believes that luck, birth, connections and/or corruption determine wealth, it will tax a lot, thus distorting allocations and making these beliefs self-sustained as well. We show how this interaction between social beliefs and welfare policies may lead to multiple equilibria or multiple steady states. We argue that this model can contribute to explain US vis a vis continental European perceptions about income inequality and choices of redistributive policies.
\end{abstract}

${ }^{*}$ This project was initiated by a lively discussion we had with Olivier Blanchard and Xavier Gabaix in February 2002; we thank them for inspiration. For helpful discussions and comments, we are thankful to Daron Acemoglu, Olivier Blanchard, Glenn Ellison, Ed Glaeser, Thomas Philippon, Andrei Shleifer, Ivan Werning, and seminar participants at MIT. Arnaud Devleeschauer provided excellent research assistance. Email: aalesina@harvard.edu, angelet@mit.edu. 


\section{A. Alesina and G.M. Angeletos}

\section{Introduction}

In the United States the redistribution of income from the rich to the poor is much more limited than in continental Western Europe ("Europe" in short), at least in part because of different perceptions about the sources of income inequality. Many more Americans than Europeans believe that poverty is due to lack of effort rather than bad luck or "social injustice". Americans perceive wealth and success as the outcome of individual talent, effort, and entrepreneurship; and, given that effort matters, they believe that the poor could raise out of poverty if they really tried. Europeans instead view poverty a trap in which unlucky people fall in. According to the World Values Survey, 71 per cent of Americans versus 40 per cent of Europeans believe that the poor could become rich if they just tried hard enough; and a larger proportion of Europeans than Americans (25 per cent versus 16 per cent) believe that income and success is mostly due to luck. ${ }^{1}$ So, who is right, the Americans who think that effort determines success, or the Europeans who think that it is mostly luck?

This paper shows that both Americans and Europeans can be correct in their beliefs about what determines income, even if there are no intrinsic differences in economic fundamentals between the two places. That is, in equilibrium it can be the case that luck is more important in Europe, while effort is more important in the United States, even if preferences, technologies, and "nature" (i.e. the exogenous statistical properties of the variables "luck", "talent", and "willingness to work") are the same in the two places. Different levels of government redistribution can then be the result of different beliefs that are fully rational, in the sense that they are unbiased and truly reflect the actual relative weights of luck and effort in the income distribution.

The key element that drives our results is the idea of "social justice" or "fairness". With these terms we capture a social preference for reducing the degree of inequality induced by luck while rewarding individual talent and effort. ${ }^{2}$ To the extent that such a preference for fairness in economic outcomes reflects a desire to limit the effect of exogenous "accidents" in one's life, it can be interpreted as a demand for social insurance.

\footnotetext{
${ }^{1}$ For a comprehensive discussion of these points, see Alesina, Glaeser and Sacredote (2001).

${ }^{2}$ See Section 2 for empirical evidence supporting our model of "fairness".
} 


\section{FAIRness AND REDistribution}

In fact, insurance is one of the main motivations of the welfare state (e.g., Rawls, 1971). In our model, we assume that the desire for social justice or insurance is embedded in preferences. But we can think of such preferences as a metaphor for some kind of a social norm that attempts to support a socially preferable outcome. ${ }^{3}$ We can also interpret "luck" as the effect of corruption, rent seeking, political subversion, theft, fraud, and the like - activities that involve large private but no social benefits, ${ }^{4}$ and are naturally treated by society as "unjust".

As the socially desired level of taxation and redistribution depends on the perceived sources of income inequality, and the actual composition of income in turn depends on anticipated tax and redistribution policies, two stable equilibria may coexist for the same "fundamentals". In the one equilibrium, taxes are high, individuals choose to invest and/or work less, and a relative large share of total income is due to luck, which in turn makes high redistribution and high taxation socially desirable. In the other equilibrium, taxes are lower, effort and investment in productive activities are higher, and a larger fraction of final income is due to effort rather than luck, which in turn sustains the lower tax rates as an equilibrium. The two regimes can be ranked in terms of aggregate welfare. Conditional on preference and ability heterogeneity, the "good" regime is unambiguously the one in which tax distortions are lower, a larger share of total income variation is due to effort rather than luck, the need for redistribution is limited, and overall economic outcomes are quite fair. Behind the veil of ignorance, however, the high-tax regime may dominate when the variation in innate talent is sufficiently high.

The interaction of economic and political choices and the consequent multiplicity that we identify in this paper are novel in the literature. In Piketty (1995), multiplicity originates in the inability of agents to learn the true costs and benefits of redistribution. Different initial priors about the costs and benefits of redistribution result to different steady-state beliefs, which support different optimal levels of taxation. A somewhat similar multiplicity arises in the recent work of Benabou and Tirole (2002). Multiple beliefs

\footnotetext{
${ }^{3}$ Cole, Mailath and Postlewaite (1992) show how different social norms may result in different reducedform preferences.

${ }^{4}$ For example, Murphy, Shleifer and Vishny $(1991,1993)$ and Angeletos and Kollintzas (1997) discuss how corruption and rent seeking are detrimental for economic growth.
} 


\section{A. Alesina and G.M. Angeletos}

are possible, not because people are unable to learn the truth, but rather because they find it optimal to deliberately bias their own perception of the truth so as to offset another genetic bias, namely procrastination. ${ }^{5}$ In Benabou (2000), on the other hand, multiplicity originates in imperfect credit and insurance markets. When inequality is low, there is strong political support for redistribution as a way to correct for capital-market imperfections, which in turn results to high efficiency and low inequality; when instead inequality is high, the rich strongly oppose redistribution, in which case low redistribution, low efficiency and high inequality are also self-sustained. In our paper, instead, multiplicity originates merely in the social desire to implement "fair" economic outcomes, even when beliefs are fully rational and there are no important differences in capital markets or other economic fundamentals. Furthermore, our focus on fairness - which is motivated by the empirical and experimental evidence we review in Section 2 - is totally new to the literature.

The rest of the paper is organized as follows. Section 2 reviews some evidence on income inequality, redistributive policies, and social preferences, which justifies our modelling approach. Section 3 introduces the basic static model. Section 4 analyzes the interaction of economic and voting choices and derives the two regimes as multiple static equilibria. Section 5 introduces dynamics and derives the two regimes as multiple steady states. Section 6 concludes. Throughout the main text, we model "luck" as exogenous noise; in the Appendix, we consider how "luck" can be reinterpreted in terms of socially unworthy activities.

\footnotetext{
${ }^{5}$ Benabou and Tirole (2002) endogenize the choice of political ideology and more specifically the choice of whether to "believe to a just world". Their work shares some common motivation with ours, but their contribution developed independently and is rather orthogonal to ours. In their model, but not in ours, people suffer from procrastination and lack of self control. At the same time, they have the ability to repress past experiences and thereby distort their own beliefs regarding what are the returns to individual effort. Given that the ex-post optimal effort is inefficiently low from an ex-ante perspective, people find it optimal ex ante to maintain a more "rosy" picture about the benefits of effort in order to "deceive" their future selves into putting more effort ex post.
} 
FAIRnESS AND REDistribution

\section{Evidence on Inequality, Redistribution and Fair- ness}

\subsection{Income inequality and redistribution}

After-tax income is inequality is much higher in the United States than in Europe. This fact, however, reflects partly the different levels of redistribution. What really matters for the politics of redistribution is the variance and skewness of the pre-tax income distribution. According to the data set by Deiniger and Squire (1996), in the mid nineties the Gini coefficient for pre-tax income in the United States was 38.5 versus an average of about 29 in Europe. Indirect measures of pre-tax income inequality, such as wage dispersion, skill premia, and returns to education, reveal a similar picture. In overall, before-tax income in the United States has both higher variance and more skewness. As for poverty, the fraction of population that receives income less than half of the country's median level is about 3 times higher in the United States than in continental Europe. ${ }^{6}$

Redistributive effort and support for the poor, on the other hand, is much lower in the United States than in Europe, as shown by both the expenditure and the revenue side of the government budget, as well as in the regulation of labor and product markets. Table 1 summarizes the composition of government spending in Europe and the United States, using data from the OECD. The overall size of government is about 50 per cent larger in Continental Europe than in the United States, about 30 versus about 45 per cent of GDP. The largest difference is indeed in transfers and other social benefits, where Europeans spend about twice as much as Americans. Table 2 summarizes "social spending", as measured by the OECD. According to this measure as well, continental European countries spend about twice as much the United States. ${ }^{7}$ Note that a large fraction of transfer to families is pensions with pay as you go systems, which imply a redistribution from young to old. However as Alesina and Glaeser (2003) document extensively but the poor retirees receive proportionally more than the rich, and the rich-poor redistributive role of pensions

\footnotetext{
${ }^{6}$ In the 1980s, that number was 18 per cent in the United States versus 5 to 8 percent in Europe. See Atkinson (1995) for more details.

${ }^{7}$ Note that the two measures of social spending in table 2 and of transfers in table 1 are not supposed to coincide because they come from tow different types of classification.
} 


\section{A. Alesina and G.M. Angeletos}

is much larger in Europe than in the United States. Interestingly there is one category in which Americans spend just as much as Europeans: health benefits. Income taxation is more progressive in Europe, and the tax burden of the rich is relatively lower in the United States. ${ }^{8}$

An important dimension of redistribution is legislation, and in particular the regulation of labor and product markets. Nickell and Layard (1999) report that the minimum wage is 39 per cent of the average wage in the United States, whereas it is 53 per cent in the European Union. Table 3, which is reproduced from Alesina, Glaeser and Sacerdote (2001), summarizes the large difference in employment protection and other labor-market regulation, using data again from Nickel and Layard (1999) and Nickel (1997). We note that Europeans and Americans differentiate by a factor of five in the duration of unemployment benefits, but not the replacement ratio; that is, Americans are protected against only short-term unemployment, but this protection is as good as in Europe.

The last observation and the point on health benefits point out that in the United States there are many programs designed to help certain characteristics of an indigent family, such as disease, disability, number of children, or short-term unemployment, but there are very few programs to help those who are poor per se. Using evidence from the Luxembourg income study, Alesina and Glaeser (2003) indeed show that the poor are generally more protected in Europe, but the difference between Europe and the United States is more limited in cases were clearly identifiable sources of poverty are evident, like disease, children to support, etc. Evidence on tax systems and the regulatory environment confirm that European countries try to protect those who are poor per se more than the United States. $^{9}$ An observation which goes in the same direction is that Americans contribute much more than Europeans to charitable contributions. One interpretation is that they prefer to give to charities rather than being taxed because with a private redistributive channel one can better choose the deserving recipients. ${ }^{10}$

\footnotetext{
${ }^{8}$ For more details, see Alesina, Glaeser and Sacerdote (2001).

${ }^{9}$ Whether or not certain types of regulation do in fact protect the very poor or certain categories which are overprotected minorities is an important issue which we do not explore here.

${ }^{10}$ See Alesina, Glaeser and Sacerdote (2001) for data and more discussion.
} 


\section{FAIRness And Redistribution}

\subsection{Social mobility and redistribution}

As noted above, most Americans believe that the poor have a fair chance of getting out of poverty, while Europeans believe that they are stuck in poverty. According to the World Values Survey, 71 per cent of Americans versus 40 per cent of Europeans believe that the poor have a chance of escaping poverty. In other words, Americans believe that their society is more mobile than what Europeans believe for their own.

The probability of upward mobility is likely to be taken into consideration by individuals when ranking redistributive policies (e.g., Benabou and Ok, 2001). The relationship between social mobility and individual demand for redistribution is studied by Ravallion and Lokshin (2000) on Russian data, Corneo and Gruner (2002) using an international survey on several OECD countries, and by Corneo (2001) for Germany and the United States. ${ }^{11}$ All these papers use cross-sectional data containing both the respondents' opinion on the desirability of redistributive policies and their self-assessments about their likelihood of being upwardly mobile, and they conclude that the latter significantly affect attitudes towards redistribution. Alesina and La Ferrara (2001) study the effect of actual rather than self-assessed mobility on individual preferences, and they find that individuals who live in more mobile places or times, are more averse to redistribution.

While there is perhaps little doubt that Americans believe that their society is mobile, and more so than Europeans think of theirs, the question remains of how in fact social mobility compare on the two sides of the Atlantic. Measuring social mobility, and especially comparing measures across countries, is extremely difficult. A recent survey by Fields and Ok (1999) finds that the evidence regarding observed social mobility in the United States and Europe is inconclusive, even though in most estimates the United States is slightly more mobile than Europe. Gottshalck and Spolaore (2002) note that there is a differences between the possibility and availability of means of social mobility and the actual observation of how much people move in the social ladder. They argue that social mobility between the middle class and the upper class is slightly higher in the United States than in Germany but the differences are quantitatively small. Looking at

\footnotetext{
${ }^{11}$ In the paper by Corneo and Gruner (2002), other motivations of the demand for redistribution, along with the political-economic channel, are taken into account, and the results are shown to differ between Eastern and Western European countries.
} 


\section{A. Alesina and G.M. Angeletos}

educational attainment, Checchi, Ichino and Rustichini (1999) find that the United States is more mobile than Italy, despite an education system that, on paper, should be more egalitarian in Italy.

In any event, the difference in social mobility across the two continents is much lower than the difference in inequality. Therefore, it seems rather implausible that it could help explain the dramatic difference in political outcomes. What is more, social mobility is itself an endogenous variable and thus may not be used as an explanatory variable. Indeed, as we discuss in Section 6, more social mobility can be merely the consequence rather than the cause of lower redistribution.

\subsection{Fairness and political outcomes}

The key assumption for our results is that agents have a desire for "social justice"; they demand that individual effort is rewarded by society; and they expect the government to intervene and "correct" economic outcomes when they feel that social competition is "unfair". We thus need evidence on both the existence of such a preference for fairness and its effect on political outcomes.

The effect of social beliefs about what determines income (luck or effort) on actual policy choices is not limited to a comparison of the United States versus Europe. Figure 1 shows a strong positive correlation between the share of social spending over GDP and the percentage of respondents to the World Values Survey who think that income is determined mostly by luck. ${ }^{12}$ As Table 4 shows, this correlation is robust to controlling for the Gini coefficient and continent dummies. The correlation looses significance if one controls for the share of the old, this is because the size of pensions depends heavily on this variable. However as pointed out above, the redistribution in favor of the poor old is much larger in continental Europe than in the US; that is, the way in which pensions are paid to the old is much more redistributive from the rich young to the poor old in continental Europe than in the US (Alesina and Glaeser, 2003). Furthermore, as Table 5 shows, if one excludes pensions, the correlation between transfer payments and beliefs in luck remains very strong. These tables also control for two political variables, the nature

\footnotetext{
${ }^{12}$ This figure is reproduced from Alesina, Glaeser and Sacerdote (2001).
} 


\section{FAIRness AND REDistribution}

of the electoral system and Presidential versus parliamentary regime, which may influence the size of transfers, as argued by Persson and Tabellini (2003). ${ }^{13}$

A country's social spending is, of course, only an aggregated measure of final outcomes, not a direct measure of individual preferences over possible political outcomes. Such a measure, however, is provided by the World Values Survey for a large sample of individuals from each surveyed country. One of the questions asks the respondent whether he (she) identifies himself (herself) as being on the left of the political spectrum. We take such "leftist political orientation" as a proxy for being in favor or redistribution and, in Table 6, we regress it against the individual's own belief about what determines income together with a series of individual- and country-specific controls. Again, the belief that luck determines income has a strong and significant effect on the probability of being leftist. ${ }^{14}$

Further survey evidence in support of the desire for fairness is in Alesina and La Ferrara (2001). They use the General Social Survey for the United States and show that individuals who think that income is determined by luck, connections, family history, etc., rather than individual effort, education, ability, etc., are much more favorable to government redistribution, even after controlling for an exhaustive set of other determinants of preferences for redistribution. These controls include the respondent income, his gender, marital status, race, age, various characteristics of where he or she lives, employment status, education, personal experience of social mobility. Similar results are reported by Fong (2002) using a different data set for the United States.

\subsection{Experimental evidence on fairness}

Fehr and Schmidt (2001) provide an extensive review of the experimental evidence on fairness, altruism, and reciprocity. In dictator games, people give a small portion of their endowment to others, even though they could keep it all. In ultimatum games, people

\footnotetext{
${ }^{13}$ The breakdown between pensions and other social spending was available only for OECD countries in a comparable form, this is why the number of observations is different in the two tables.

${ }^{14}$ The other variables have the expected sign and are very similar to the results reported in Alesina Glaeser and Sacerdote (2001). That is, income, education and being American influence negatively the probabiltiy of being leftist; leftists tend to live in cities and have fewer children; and the oldest (above 65) are significatively less leftist than all the other age groups.
} 


\section{A. Alesina and G.M. Angeletos}

are ready to suffer a monetary loss themselves just to punish behavior that is considered "unfair". In gift exchange games, on the other hand, people are willing to suffer a loss in order to reward actions that they perceive as generous or fair. Finally, in public good games, cooperators tend to punish free-riders. These findings are very robust to changes in the size of monetary stakes or the background of players. In short, there is plenty experimental evidence that people have an innate desire for fairness, and are ready to punish unfair behavior. What is more, the existing evidence rejects the hypothesis that altruism takes merely the form of absolute inequity aversion. People instead appear to desire equality relative to some reference point, namely what they consider as a "fair" outcome, which is precisely what we assume in our model.

Further support in favor of our concept of fairness is provided by the evidence that experimental outcomes are sensitive to whether the roles or the initial endowments of the experimental subjects are assigned randomly or as a function of previous achievement. In ultimatum games, Hoffman and Spitzer (1985) and Hoffman et al. (1998) find that those who make proposals are more likely to make unequal offers, and responders are less likely to reject unequal offers, when the proposers have outscored the respondents in a preceding trivia quiz or game, and even more if they have been explicitly told that they have "earned" their roles in the ultimatum game on the basis of their preceding performance. In double action market experiments, Ball et al. (1996) report a similar sensitivity of the division of surplus between buyers and sellers on whether market status is random or earned. Finally, in a public good game where groups of people with unequal endowments vote over two alternative contribution schemes, Clark (1998) finds that members of a group are more likely to vote for the scheme that redistributes less from the rich to the poor members of the same group, when initial endowments depend on previous relative performance in a general-knowledge quiz rather than been randomly assigned. In short, there is always a conflict between self interest and fairness concerns, but how this conflict is resolved, and whether experimental subjects regard any given inequality in final outcomes as justifiable or unfair, seems to depend strongly on whether such inequality derives from achievement or random luck.

Last but not least, psychologists, sociologists and political scientists have long stressed the importance of a sense of fairness and justice in the private, social and political life of 
FAirness ANd Redistribution

men. People enjoy great satisfaction when they know (or believe) that they live in a just world, where hard work and good behavior will ultimately pay off; they strongly believe that one should get what he deserves and, conversely, that one should deserve whatever he gets; they are outraged in the face of unfair behavior and they demand that justice prevails. $^{15}$

\section{The Basic Model}

Consider a non-overlapping generation model, in which each generation consists of a large number of agents (a $[0,1]$ continuum), who live for two periods. In each period of life, agents engage in investment and productive activities, such as accumulation of physical or human capital, work, entrepreneurship, etc.. In the middle of their life, agents vote over the tax and redistributive policy of their government. And at the end of their life, agents consume all their disposable income. As there are no links across generations, the economy is essentially static, and we can characterize economic conditions and outcomes in one generation without reference to any other generation. We consider inter-generational links later, in Section 5.

\subsection{Heterogeneity, technologies, and preferences}

The investment and productive activities of the first period of life require effort. For the moment we assume that everybody has the same cost of effort. Income is the combined outcome of inherent talent, investment during the first period of life, effort during the second period of life, and luck:

$$
y_{i}=A_{i}\left[\alpha k_{i}+(1-\alpha) e_{i}\right]+\eta_{i} .
$$

$y_{i}$ denotes the income agent $i$ receives in the second period of life, $k_{i}$ the investment he makes in the first period of life, and $e_{i}$ the effort he exerts in the second period of life. $\alpha \in[0,1]$ is a technological constant, which can be interpreted as the share of income that represents return to past investment and that is sunk when the tax rate is

\footnotetext{
${ }^{15}$ For a detailed discussion and more references, see Lerner (1982) and Benabou and Tirole (2002).
} 


\section{A. Alesina and G.M. Angeletos}

fixed. $A_{i}$ represents the inherent talent and skills of agent $i$. Finally, $\eta_{i}$ is i.i.d. noise, which we interpret as pure random luck. In the Appendix, we discuss how one can influence his "luck" by engaging in "bad effort", that is, how "luck" can be reinterpreted as corruption, rent seeking, political subversion, theft, fraud, or other forms of socially unworthy activities.

We note that heterogeneity in productivity $A_{i}$ is meant to capture exogenous innate differences, not endogenous acquired differences, such as in education, learning by doing, and other forms of human capital. The latter should instead be interpreted as part of $k_{i}{ }^{16}$ Also, the case that productivity and human capital reflects, not only one's own choices during his life, but also the wealth and history of his family, is examined in Section 5 .

Consumption in the second period of life is given by

$$
c_{i} \leq(1-\tau) y_{i}+G \text {. }
$$

$\tau$ denotes the flat-rate income tax the government imposes in the second period and $G$ represents a lump sum transfer. This redistributive scheme is widely used in the literature following Romer (1975) and Meltzer and Richard (1981), because it is the simplest one to model. The qualitative nature of our message is not unduly sensitive to the precise nature of this scheme.

Individual preferences are given by

$$
u_{i}=U_{i}\left(c_{i}, k_{i}, e_{i}, \Omega\right)=c_{i}-\frac{1}{\beta_{i}} \varphi\left(k_{i}, e_{i}\right)-\gamma \Omega .
$$

The first term represents the utility of consumption. The second term represents the costs of first-period investment and second-period effort. $\beta_{i}$ parametrizes the willingness to postpone consumption and work hard: a low $\beta_{i}$ captures impatience or laziness, a high $\beta_{i}$ captures "care for the future". or "love for work". If agents suffered from procrastination and hyperbolic discounting, $\beta_{i}$ could also be interpreted as the degree of self control. ${ }^{17}$

\footnotetext{
${ }^{16}$ In that case, $k_{i}$ and $e_{i}$ may be complements; such complementarities would complicate the algebra but would not matter for our results.

${ }^{17}$ In that case, we would need to distinguish between ex ante and ex post preferences. For example, we could let $\beta_{i}=1$ for all $i$ ex ante, whereas $\beta_{i} \leq 1$ and $\operatorname{Var}\left(\beta_{i}\right)>0$ ex post. Such a modification would complicate the algebra but would not change fundamentally our equilibrium analysis. A "sophisticated" median voter would try to offset the temptation to procrastinate when choosing the optimal tax rate, which would decrease the incentive to tax, but the possibility of multiple equilibria would remain.
} 
For simplicity, and without serious loss of generality, we let $\varphi$ be quadratic:

$$
\varphi\left(k_{i}, e_{i}, \beta_{i}\right)=\frac{\alpha}{2} k_{i}^{2}+\frac{1-\alpha}{2} e_{i}^{2} .
$$

The coefficients $\alpha / 2$ and $(1-\alpha) / 2$ are merely a normalization. Finally, $\Omega$ is a measure of "social injustice", and $\gamma$ measures the strength of the social demand for "fairness".

Remark. We have introduced heterogeneity in $A_{i}$ and $\beta_{i}$ in order to generate endogenous variation in the "fair" levels of income. No differences in exogenous talent (i.e., $A_{i}=A$ for all $i$ ) or no difference in laziness (i.e., $\beta_{i}=\beta$ for all $i$ ) are two special cases of our model with the same qualitative implications as the general specification.

\subsection{Fairness and social injustice}

Following the evidence in Section 2 that most people share a common concern for fairness and a common perception that one should get what he deserves and deserve what he gets, we define

$$
\Omega=\mathbb{E} \int_{i}\left(c_{i}-\widehat{c}_{i}\right)^{2}
$$

and

$$
\widehat{c}_{i} \equiv \widehat{y}_{i} \equiv A_{i}\left[\alpha k_{i}+(1-\alpha) e_{i}\right]=y_{i}-\eta_{i}
$$

The latter represent the "fair" or "ideal" levels of consumption and income for agent $i$, that is, what the agent should enjoy on the basis of his talent and effort. $\Omega$ then gives an aggregate measure of the distance between actual and fair levels of consumption in the society. In the absence of taxation, $\Omega$ would measure how unfair is the pre-tax income distribution; now $\Omega$ measures how unfair economic outcomes remain after redistribution. Note that the expectation operator $\mathbb{E}$ appears in $\Omega$ because $\left(A_{i}, \beta_{i}, \eta_{i}\right)$, and thus $\left(k_{i}, e_{i}, \widehat{c}_{i}\right)$, are private information to agent $i$. The government and the society as a whole observe the total income of each agent, but can not tell whether this income is the fruits of talent and effort or the outcome of pure luck (or the outcome of corruption). 


\section{A. Alesina And G.M. Angeletos}

\subsection{The Government}

The government chooses the tax rate $\tau$ and the level of redistribution or spending $G$, subject to the following budget constraint:

$$
G \leq \int_{i} \tau y_{i}=\tau \mathbb{E} y_{i}
$$

We assume that the policy is chosen with one person one vote rule and the median voter theorem holds. There will be two motivation for redistribution. One is to partly correct for the effect of luck on income because of the demand for fairness. The second one, in the event that the median of the population is poorer than the mean, is the standard "selfish" redistribution a la Meltzer and Richard (1981).

\section{The Politico-economic Equilibrium}

The general equilibrium of the economy is naturally defined as:

Definition 1 An equilibrium is a tax rate $\tau$ and a collection of individual plans $\left\{k_{i}, e_{i}\right\}_{i \in[0,1]}$ such that $(i)$ the plan $\left(k_{i}, e_{i}\right)$ maximizes the utility of agent $i$ for every $i$, and $(i i)$ the tax rate $\tau$ maximizes the utility of the median voter.

Using (2), (6) and (7), (5) reduces to

$$
\Omega=\mathbb{E} \int\left\{\left[(1-\tau) y_{i}+\tau \mathbb{E} y_{i}\right]-\widehat{y}_{i}\right\}^{2} .
$$

Suppose that $\eta_{i} \equiv y_{i}-\widehat{y}_{i}$ is independent of $\widehat{y}_{i}$; this will turn to be true in equilibrium if and only if luck $\eta_{i}$ is independent of talent $A_{i}$ and patience $\beta_{i}$, which we assume for simplicity. Then, from (8) we obtain social injustice as a weighted average of the "variance decomposition" of income inequality:

$$
\Omega=\tau^{2} \operatorname{Var}\left(\widehat{y}_{i}\right)+(1-\tau)^{2} \operatorname{Var}\left(\eta_{i}\right) .
$$

Note that the weights depend on the level of redistribution, namely $\tau$. If minimizing $\Omega$ were the only purpose of taxation, and the income distribution were exogenous, the equilibrium tax rate would be given simply by:

$$
\frac{1-\tau}{\tau}=\frac{\operatorname{Var}\left(\widehat{y}_{i}\right)}{\operatorname{Var}\left(\eta_{i}\right)}
$$




\section{FAIRness And Redistribution}

The right-hand side represents a kind of signal-to-noise ratio in the income distribution; and as the goal of redistribution is to eliminate the effect of noise on income inequality, the optimal tax rate is decreasing is this signal-to-noise ratio. However, the income distribution and the corresponding signal-to-noise ratio are endogenous in the economy, as they depend on the investment and effort choices made by all agents, which we now examine.

\subsection{Investment and effort choice}

Consider the investment and effort decisions of agent $i$. He chooses $k_{i}$ and $e_{i}$ so as to maximize

$$
u_{i}=(1-\tau) A_{i}\left[\alpha k_{i}+(1-\alpha) e_{i}\right]+G-\frac{\alpha}{2 \beta_{i}} k_{i}^{2}-\frac{(1-\alpha)}{2 \beta_{i}} e_{i}^{2}-\gamma \Omega,
$$

taking $\tau, G$, and $\Omega$ as given. Since agents choose $k_{i}$ before $\tau$ is fixed, first-period investment is a function of the anticipated tax rate and is sunk when the actual tax rate is chosen. On the other hand, agents choose second-period effort $e_{i}$ ex post, contingent on the realized tax and the investment the made before. To distinguish the anticipated tax rate from the realized one, we henceforth denote the former by $\bar{\tau}$ and the latter by $\tau$. Of course, $\bar{\tau}=\tau$ in any perfect-foresight equilibrium, but we adopt the different notation for the shake of clarity.

The first order conditions with respect to $k_{i}$ and $e_{i}$ imply:

$$
k_{i}=(1-\bar{\tau}) \beta_{i} A_{i} \quad \text { and } \quad e_{i}=(1-\tau) \beta_{i} A_{i} .
$$

Next, substituting into (6) yields

Lemma 1 Let $\bar{\tau}$ denote the ex-ante anticipated tax rate and $\tau$ the ex-post realized one. The "fair" component on income is given by

$$
\widehat{y}_{i}=[1-\alpha \bar{\tau}-(1-\alpha) \tau] \delta_{i},
$$

where $\delta_{i} \equiv \beta_{i} A_{i}^{2}$. Income is thus increasing in own talent, patience, or willingness to work, and decreasing in the tax rate. 


\section{A. Alesina and G.M. Angeletos}

Therefore, exogenous heterogeneity in either talent $\left(A_{i}\right)$ or impatience and laziness $\left(\beta_{i}\right)$ translates to endogenous heterogeneity in investment and effort $\left(k_{i}, e_{i}\right)$ and thereby in the fair component of income $\left(\widehat{y}_{i}\right)$.

\subsection{The median voter and the optimal tax}

Consider an arbitrary agent $i$. From (2) and (13),

$$
c_{i}=(1-\tau) y_{i}+\tau \mathbb{E} y=(1-\tau) \eta_{i}+[\alpha(1-\bar{\tau})+(1-\alpha)(1-\tau)]\left[\delta_{i}+\tau\left(\mathbb{E} \delta-\delta_{i}\right)\right]
$$

From (4) and (12),

$$
\phi\left(k_{i}, e_{i}\right)=\frac{1}{2}\left[\alpha(1-\bar{\tau})^{2}+(1-\alpha)(1-\tau)^{2}\right] \delta_{i} \beta_{i}
$$

Substituting the above into (3), we conclude that equilibrium utility is given by

$$
u_{i}=(1-\tau) \eta_{i}+\frac{1}{2}\left[1-\alpha \bar{\tau}^{2}-(1-\alpha) \tau^{2}\right] \delta_{i}+[1-\alpha \bar{\tau}-(1-\alpha) \tau] \tau\left(\mathbb{E} \delta-\delta_{i}\right)-\gamma \Omega
$$

On the other hand, social injustice is

$$
\Omega=\tau^{2} \operatorname{Var}\left(\widehat{y}_{i}\right)+(1-\tau)^{2} \operatorname{Var}\left(\eta_{i}\right) .
$$

$\operatorname{Var}\left(\eta_{i}\right)$, which measures the contribution of luck, is exogenous, but $\operatorname{Var}\left(\widehat{y}_{i}\right)$, which measures the contribution of talent, effort and investment, is endogenous. From Lemma 1,

$$
\operatorname{Var}\left(\widehat{y}_{i}\right)=[1-\alpha \bar{\tau}-(1-\alpha) \tau]^{2} \operatorname{Var}\left(\delta_{i}\right)
$$

Therefore, equilibrium social injustice is given by

$$
\Omega=\tau^{2}[1-\alpha \bar{\tau}-(1-\alpha) \tau]^{2} \sigma^{2}+(1-\tau)^{2} v^{2}
$$

where $\sigma^{2} \equiv \operatorname{Var}\left(\delta_{i}\right) \equiv \operatorname{Var}\left(\beta_{i} A_{i}^{2}\right)$ and $v^{2} \equiv \operatorname{Var}\left(\eta_{i}\right)$.

From (14) and (5), it follows that $u_{i}$ is single-picked in $\tau$ and the $\tau$ that maximizes $u_{i}$ is a decreasing function of $\delta_{i}$ and an increasing function of $\eta_{i}$. For simplicity, assume that the distribution of $\eta_{i}$ is symmetric and a law of large numbers holds with respect to $\eta_{i}$ for any $\delta_{i}$. The median-voter theorem then applies with respect to $\delta_{i}$ and the median voter 


\section{FAIRness AND REDistribution}

corresponds to an agent $i$ such that $\delta_{i}=\delta_{m}$ and $\eta_{i}=0$, where $\delta_{m}$ denotes the median of the distribution of $\delta_{i}$.

Following (14), the utility of the median voter is given by

$$
u_{m}=\kappa-\frac{1}{2}(1-\alpha) \tau^{2} \delta_{m}+[1-\alpha \bar{\tau}-(1-\alpha) \tau] \tau\left(\mathbb{E} \delta-\delta_{m}\right)-\gamma \Omega,
$$

where $\kappa \equiv\left(1-\alpha \bar{\tau}^{2}\right) \delta_{i} / 2$. Note that $\kappa$ is perceived as a constant when $\tau$ is chosen, meaning that the median voter does not internalize the adverse effect of the tax rate on past investment choices. ${ }^{18}$ On the other hand, the median voter does take into account the distortion of contemporaneous effort; this efficiency cost is reflected in the second term above. The third term in (17) is the net transfer the median voter receives from the government, reflecting the fact that a positive tax rate effectively redistributes from the mean to the median of the income distribution. This term introduces a "selfish" motive for redistribution, as in Meltzer and Richard (1981), whereas the last term captures an "altruistic" motive for redistribution, originating in the social concern for fairness.

In order to focus on the implications of fairness, in the remainder of this section we restrict $\delta_{m}=\mathbb{E} \delta_{i}$, so that the mean and the median of the income distribution coincide. We extend our results to the more general case, $\delta_{m}<\mathbb{E} \delta_{i}$, in Section 4.4. Normalizing then $\delta_{m}=2$, the median voter's utility reduces to

$$
u_{m}=\kappa-(1-\alpha) \tau^{2}-\gamma \Omega
$$

with $\Omega$ given by (16).

The ex post "optimal" tax rate $\tau$ maximizes the utility of the median voter, $u_{m}$, taking the ex ante anticipated tax rate $\bar{\tau}$ as given. It follows:

Lemma 2 Let $\sigma>0$ measure the exogenous variation in talent, patience, or willingness to work, $v>0$ the exogenous amount of pure luck, $\gamma \geq 0$ the desire for social justice, and $\alpha \in(0,1)$ the portion of income that is sunk when the tax rate is voted. Suppose that the mean and the median of the income distribution coincide and define

$$
f(\bar{\tau}) \equiv \arg \min _{\tau \in[0,1]}\left\{\tau^{2}\left[(1-\alpha)+\left(\gamma \sigma^{2}\right)(1-\alpha \bar{\tau}-(1-\alpha) \tau)^{2}\right]+(1-\tau)^{2}\left(\gamma v^{2}\right)\right\}
$$

\footnotetext{
${ }^{18}$ In other words, we have assumed that the median voter lacks commitment. We explain why this a reasonable assumption in 4.5 .
} 


\section{A. Alesina and G.M. Angeletos}

$f$ represents the best-response function of the median voter against market expectations. That is, when the ex-ante anticipated tax rate is $\bar{\tau}$, the ex-post optimal tax rate is $f(\bar{\tau})$. If $\gamma=0, f(\bar{\tau})=0$ for all $\bar{\tau} \in[0,1]$. If instead $\gamma>0$, the optimal tax is $f(\bar{\tau})>0$ for all $\bar{\tau} \in[0,1]$ and is decreasing in $\sigma$ and increasing in $v$ and $\alpha$.

The intuition is simple. If there were no concern about fairness $(\gamma=0)$, the optimal tax is zero, as redistribution has only costs and no benefits from the perspective of the median voter (who is also the mean agent). When instead the society desires fair economic outcomes $(\gamma>0)$, the optimal tax will trade less efficiency for more fairness. If there is a concern for fairness, then society chooses a positive level of redistribution in order to correct for the effect of "luck" on income inequality. As $\sigma$ increases, more of the observed income variation is due to luck, and the higher is the optimal tax rate. The opposite consideration holds for larger $v$, as this implies more income variability due to ability and effort. The relationship between the ex-ante anticipated tax rate $(\bar{\tau})$ and the ex-post optimal rate $(\tau)$ is generally non-monotonic. In fact an increase in $\bar{\tau}$ has an unambiguous adverse effect on the fairness of the income distribution, as it distorts investment, but an increase in $\tau$ has two opposite effects. On the one hand, like in the case of $\bar{\tau}$, a higher $\tau$ reduces the "fair" component of income variation, as it distorts effort. On the other hand, a higher $\tau$ redistributes more from the poor to the rich and may thus "correct" for the effect of luck. When $\bar{\tau}$ is small, the second effect dominates; $\tau$ increases with $\bar{\tau}$ in order to expand redistribution and thus "correct" for the relatively larger effect of luck. When instead $\bar{\tau}$ is high, the first effect dominates; $\tau$ falls with $\bar{\tau}$ in order to encourage more effort and thus "substitute" for the adverse effect of a higher $\bar{\tau}$.

\subsection{General equilibrium}

From Lemma 1, the "signal-to-noise" ratio in the income distribution is given by

$$
\frac{\operatorname{Var}\left(\widehat{y}_{i}\right)}{\operatorname{Var}\left(\eta_{i}\right)}=[1-\alpha \bar{\tau}-(1-\alpha) \tau]^{2} \frac{\sigma^{2}}{v^{2}}
$$

and is decreasing in the anticipated tax rate as long as part of income is sunk when the tax is chosen (that is, $\alpha>0$ ). On the other hand, minimizing social injustice $\Omega$ can be interpreted as minimizing the effect of "noise" on consumption variation. The ex post 


\section{FAIRNESS AND REDISTRIBUtion}

optimal tax is thus higher the lower the higher the signal-to-noise ratio in the income distribution. It is this interaction between the signal-to-noise ratio that the tax rate that opens the door to multiple equilibria.

In any equilibrium, expectations must be validated; the ex-post optimal and the exante anticipated tax rates must thus coincide. Combining Lemmas 1 and 2, we conclude:

Proposition 1 Suppose that the median and the mean coincide. An equilibrium is any fixed point $\tau=f(\tau)$, where $f$ is given by 19. If $\gamma=0$, the unique equilibrium is $\tau=0$. If instead $\gamma>0$, the tax rate is $\tau \in(0,1)$ in any equilibrium; the equilibrium is unique when $\gamma$ is sufficiently small or when $v / \sigma$ is either sufficiently small or sufficiently large; but there are two stable equilibria (and one unstable) when $\gamma$ is sufficiently high and $v / \sigma$ takes moderate values.

Therefore, provided that part of the effort and investment choices are sunk when the tax rate is chosen and the society cares about the fairness of economic outcomes, the economy is prone to multiple equilibria, unless the amount of exogenous heterogeneity in talent and willingness to work is either too high (in which case only a low-tax equilibrium survives) or too small (in which case only a high-tax equilibrium survives). ${ }^{19}$ The possibility of multiple equilibria is easy to see when $v / \sigma \approx 0$ and $\alpha \approx 1$, in which case both the exogenous amount of luck and the ex-post cost of taxation are almost zero. There are then two stable equilibria, one in which $\tau \approx 0$ and one in which $\tau \approx 1$.

Figure 2 illustrates an example of multiple equilibria. The solid curve depicts the best-response function (19) for an economy in which $\gamma=1, \alpha=1 / 2, \sigma=2.5$, and $v=1$ (meaning that, in the absence of taxation, $70 \%$ of the income variation would be due to differences in talent and effort and 30\% due to random luck, and that half of income is predetermined when the tax is chosen). This curve has three intersection points with the

\footnotetext{
${ }^{19}$ In light of the recent critique by Morris and Shin (2000), one may worry that our multiplicity result would break down in we were to relax the common-knowledge assumption and introduce idiosyncratic noise in the observation of economic fundamentals. However, Angeletos, Hellwig and Pavan (2002) show that the Morris-Shin selection argument breaks, and multiplicity survives, once policy is endogenized in macroeconomic environments with strategic complementarities. Besides, in the dynamic extension we consider in Section 6, the two tax regimes reemerge as two stable steady states of a unique equilibrium path, in which case the Morris-Shin critic is simply irrelevant.
} 


\section{A. Alesina and G.M. Angeletos}

$45^{\circ}$ line, each corresponding to a different politico-economic equilibrium. The two extreme points ( $U S$ and $E U$ ) correspond to stable equilibria, while the middle one corresponds to an unstable one. In point $E U$, the anticipation of a high tax induces agents to exert little effort. This in turn implies that the bulk of income heterogeneity is due to luck and makes it ex post optimal for society to undertake large redistribution programs by imposing high taxes, thus vindicating initial expectations. In point $U S$, instead, the anticipation of a low tax induces agents to exert high effort and implies that income variation is mostly the outcome of heterogeneity in talent and effort, which in turn makes a low tax self-sustained in the political process.

As long as there is both a desire and a cost for redistribution, and the exogenous amount of luck is neither too large nor too small as compared to exogenous heterogeneity in talent, a high- and a low-tax regime are bound to coexist. But if $v / \sigma$ was so large that the effect of luck always dominated the effect of talent and effort in shaping the income distribution, then only the high-tax regime would survive. Such a situation is illustrated by the upper dashed line in Figure 2. Finally, if $\gamma, v / \sigma$, or $\alpha$ were very small, so that either there is no social desire for fairness, or there is no need for redistribution, or the cost of taxation is too high, then only the low-tax regime would survive. Such a situation is illustrated by the lower dashed lined in Figure 2.

\subsection{Self-interested redistribution}

We now allow the median of the income distribution to be lower than the mean, namely $\delta_{m}<\mathbb{E} \delta$, and thus introduce a selfish motive for redistribution, as in Meltzer and Richard (1981).

Let $\Delta \equiv \mathbb{E} \delta-\delta_{m}$ be the distance between the mean and the median of the pre-tax income distribution, which can be interpreted as a measure of pre-tax income inequality. As before, normalize $\delta_{m}=2$. From (17), the median voter's utility is now given by

$$
u_{m}=\kappa-(1-\alpha) \tau^{2}-\gamma \Omega+\tau[1-\alpha \bar{\tau}-(1-\alpha) \tau] \Delta,
$$

while social injustice is again given by (16). We conclude that the best-response function 
for the median voter becomes

$$
\begin{aligned}
& f(\bar{\tau}) \equiv \arg \min _{\tau \in[0,1]}\left\{\tau^{2}\left[(1-\alpha)+\left(\gamma \sigma^{2}\right)(1-\alpha \bar{\tau}-(1-\alpha) \tau)^{2}\right]+(1-\tau)^{2}\left(\gamma v^{2}\right)\right. \\
& -\tau[1-\alpha \bar{\tau}-(1-\alpha) \tau] \Delta\}
\end{aligned}
$$

The only difference from (19) is the last term, which captures the Meltzer-Richard effect. And again, a politico-economic equilibrium corresponds to any fixed point $\tau=f(\tau)$.

Note that $f(\bar{\tau})$ increases with $\Delta$ for any $\bar{\tau} \in[0,1]$. By implication, any stable fixed point of $f$ is locally increasing in $\Delta$. This reflects simply the fact that, the poorer the median voter is relatively to the mean, the higher the incentive to redistribute. As $\Delta$ increases, the optimal tax rate trades less of the public good (fairness) for more of the private good (self-interest redistribution). When $\Delta$ is sufficiently large, so that the selfish motive dominates, or $\gamma$ is close to zero, so that there is little concern for fairness, a unique equilibrium survives. But otherwise, the possibility of multiple equilibria remains.

The above results highlight that there are two forces driving the equilibrium level of redistribution: The absolute extent of income inequality (as measured by $\Delta$ ) and the social value attributed to the fairness of economic outcomes (as measured by $\gamma$ ). Provided that the latter is sufficiently strong, it is perfectly possible that the observed level of taxation is lower in a country with more income inequality, even if there is no difference in underlying fundamentals. Such an observation cannot be explained by a pure Meltzer-Richard model, as in the absence of a social demand for fairness a unique equilibrium survives, in which redistributive effort is higher the higher the income inequality. ${ }^{20}$

\subsection{Comments}

First, the two equilibria can easily be ranked from the perspective of the median voter, namely the one with lower taxes is always superior: There are less distortions, more investment, and more aggregate income; and the ex-post heterogeneity in income is due relatively more to ability than to luck, a socially desirable outcome. On the other hand, behind the veil of ignorance (before learning either $A_{i}$ or $\eta_{i}$ ), the equilibrium with high

\footnotetext{
${ }^{20}$ For cross-country evidence which also gives little support for a pure Meltzer-Richards model of redisitribution, see Perotti (1996).
} 


\section{A. Alesina and G.M. Angeletos}

redistribution might be preferable if the variation in idiosyncratic productivities is sufficiently large; that is, if you do not know whether you will be born with high or low ability, you may prefer to be born in Europe rather than the United States, as the European regime provides more insurance against such genetic risk.

Second, it is perfectly possible that the "good" equilibrium has more inequality than the "bad" equilibrium: If $\sigma$ is high relative to $v, \operatorname{Var}\left(y_{i}\right)$ and $\operatorname{Var}\left(c_{i}\right)$ will be larger in the "good" equilibrium, but the "variance decomposition" will be fairer.

Third, the multiplicity of equilibria arises because of the goal of social justice. If the median voter targeted inequality per se, and placed no weight on the nature of the source of income the multiplicity of equilibria would disappear. This, in fact, were true both in the case in which the mean and median coincided and in the case in which the median was poorer than the mean.

Finally, it is unrealistic to think that an economy could simply "jump" from one tax regime to another by simply revising equilibrium expectations from one day to another. In the next section, we consider a dynamic extension, in which the two regimes emerge as multiple steady states. History then plays an important role in determining what beliefs the society holds and what redistributive policies it selects. Similarly, while only the lowtax regime would survive in the static economy if the society could credibly commit on its tax and redistributive policies before agents make their early-in-life investment and effort decisions, such commitment will be of little value in the dynamic economy, when wealth and income are largely determined by family history.

\section{Intergenerational Transfers and History Dependence}

One important determinant of wealth and success in life is being born in a wealthy family. In order to explore this issue, we now introduce intergenerational wealth transfers and parental investment (e.g., bequests, education, status, etc.) that link individual income to family history and birth. ${ }^{21}$ In order to concentrate on beliefs about the history of the wealth distribution rather than expectations about future taxation, we abstract from

\footnotetext{
${ }^{21}$ For a recent discussion of intergenerational transfer of wealth and its effect on effort choices and entrepreneurship, see Caselli and Gennaioili (2002)
} 


\section{FAIRnESS AND Redistribution}

investment choices made within a generation before the tax is set, and thus shut down the source of multiple self-fulfilling equilibria that we had in the benchmark static model. The optimal rate of taxation and redistribution is now uniquely determined for any given generation, but it depends on the whole history of the decomposition of wealth.

\subsection{The environment}

Consider an economy of non-overlapping generations indexed by $t \in\{. .,-1,0,1, \ldots\}$. Each generation lives for one period. Within each generation, there is a single effort choice, made after the tax is voted on. Parents enjoy utility for leaving a bequest to their children; by "bequests" we mean, not only monetary transfers, but also all other sorts of parental investment. Let $c_{t}^{i}$ denote the consumption of family $i$ in generation $t$, and $k_{t}^{i}$ the bequest the family leaves to the next generation. ${ }^{22}$ Preferences are now given by

$$
u_{t}^{i}=U^{i}\left(c_{t}^{i}, k_{t}^{i}, e_{t}^{i}, \Omega_{t}\right)=V\left(c_{t}^{i}, k_{t}^{i}\right)-\frac{1}{\beta_{t}^{i}} \varphi\left(e_{t}^{i}\right)-\gamma \Omega_{t}
$$

The first term represents the utility from consumption and bequests, the second term is the disutility of effort, and the last term captures the demand for fairness. As in the benchmark model, $\beta_{t}^{i}$ parametrizes "laziness" and $\varphi$ is quadratic:

$$
\varphi\left(e_{t}^{i}\right)=\frac{1}{2}\left(e_{t}^{i}\right)^{2}
$$

For simplicity, we also assume a Cobb-Douglas aggregator over consumption and bequests:

$$
V\left(c_{t}^{i}, k_{t}^{i}\right)=\frac{1}{(1-\alpha)^{1-\alpha} \alpha^{\alpha}}\left(c_{t}^{i}\right)^{1-\alpha}\left(k_{t}^{i}\right)^{\alpha} .
$$

The constant $(1-\alpha)^{1-\alpha} \alpha^{\alpha}$ is just an innocuous normalization. As the fraction of wealth allocated to bequests will turn to equal $\alpha$, the coefficient $\alpha$ can be interpreted as an intergenerational discount factor.

The budget constraint for household $i$ in generation $t$ is given by

$$
c_{t}^{i}+k_{t}^{i} \leq\left(1-\tau_{t}\right) y_{t}^{i}+G_{t},
$$

\footnotetext{
${ }^{22}$ This is of course a short cut, which is easier to model than adding the utility function of the children into that of the parents.
} 


\section{A. Alesina And G.M. Angeletos}

while the budget constraint for the government is

$$
G_{t}=\tau_{t} \mathbb{E} y_{t}^{i}
$$

Pre-tax income (or wealth) is now given by the sum of effort, luck, and parental investment:

$$
y_{t}^{i}=A_{t}^{i} e_{t}^{i}+\eta_{t}^{i}+k_{t-1}^{i}
$$

$A_{t}^{i}$ represents, as before, innate talent, which is independent of family history. To the extent that productivity reflects child-rearing, education, and other shorts of parental investment, we capture its effect on income through $k_{t-1}^{i}$, not $A_{t}^{i}{ }^{23}$ Finally, $\eta_{t}^{i}$ is again i.i.d. noise, which captures exogenous luck within the life of the agent.

Finally, for the measure of fair outcomes and social injustice, we must now take into account not only the contemporaneous effect of luck but also the propagation of luck through intergenerational transfers. Suppose $\tau_{t}$ were zero in all $t$. Then, iterating (25) backward would give

$$
\begin{aligned}
y_{t}^{i} & =\left(A_{t}^{i} e_{t}^{i}+\eta_{t}^{i}\right)+k_{t-1}^{i}= \\
& =\left(A_{t}^{i} e_{t}^{i}+\eta_{t}^{i}\right)+\alpha\left(A_{t-1}^{i} e_{t-1}^{i}+\eta_{t-1}^{i}\right)+\alpha k_{t-2}^{i}=\ldots= \\
& =\sum_{s \leq t} \alpha^{s-t} A_{s}^{i} e_{s}^{i}+\sum_{s \leq t} \alpha^{s-t} \eta_{s}^{i}
\end{aligned}
$$

Assuming that bequests and parental investments are considered fair only to the extent that they reflect effort and talent, not pure luck or undeserved privileges, the "fair" or "ideal" level of wealth is the cumulative effect of effort and talent,

$$
\widehat{y}_{t}^{i} \equiv \sum_{s \leq t} \alpha^{s-t} A_{s}^{i} e_{s}^{i}
$$

while the residual

$$
y_{t}^{i}-\widehat{y}_{t}^{i}=\sum_{s \leq t} \alpha^{s-t} \eta_{s}^{i}
$$

represents the cumulative effect of luck throughout the family's history. The corresponding fair levels of consumption and bequests are $\widehat{c}_{t}^{i}=(1-\alpha) \widehat{y}_{t}^{i}$ and $\widehat{k}_{t}^{i}=\alpha \widehat{y}_{t}^{i}$. Social injustice

\footnotetext{
${ }^{23}$ Introducing a production complementarity between parental investment, $k_{t-1}^{i}$, and individual effort, $e_{t}^{i}$, would complicate the algebra, but would not alter our qualitative findings.
} 


\section{FAirness and Redistribution}

is now the distance between actual and fair levels of consumption and bequests:

$$
\Omega_{t}=\mathbb{E} \int\left\{\left[c_{t}^{i}+k_{t}^{i}\right]-\left[\widehat{c}_{t}^{i}+\widehat{k}_{t}^{i}\right]\right\}^{2} .
$$

By (23), social injustice is equivalently the distance between actual disposable income and fair income,

$$
\Omega_{t}=\mathbb{E} \int\left\{\left[\left(1-\tau_{t}\right) y_{t}^{i}+\tau\left(\mathbb{E} y_{t}^{i}\right)\right]-\widehat{y}_{t}^{i}\right\}^{2},
$$

which is exactly the same as in the benchmark model (see condition (8)).

\subsection{Optimal allocations}

Maximizing (22) subject to the budget constraint (23) implies that the optimal consumption and saving choice is

$$
\begin{gathered}
c_{t}^{i}=(1-\alpha)\left[\left(1-\tau_{t}\right) y_{t}^{i}+\tau_{t} \bar{y}_{t}\right], \\
k_{t}^{i}=\alpha\left[\left(1-\tau_{t}\right) y_{t}^{i}+\tau_{t} \bar{y}_{t}\right] .
\end{gathered}
$$

Substituting into (22), maximizing subject to (25) implies that the optimal effort is

$$
e_{t}^{i}=\left(1-\tau_{t}\right) A_{t}^{i} \beta_{t}^{i}
$$

Fair income is

$$
\widehat{y}_{t}^{i}=\sum_{s \leq t} \alpha^{s-t} A_{s}^{i} e_{s}^{i}=\sum_{s \leq t} \alpha^{s-t}\left(1-\tau_{s}\right) \delta_{s}^{i},
$$

where $\delta_{t}^{i} \equiv \beta_{t}^{i}\left(A_{t}^{i}\right)^{2}$. Substituting the government budget into (29), and assuming that $\delta_{t}^{i}$ and $\eta_{t}^{i}$ are uncorrelated with each other, which ensures that $\widehat{y}_{t}^{i}$ and $y_{t}^{i}-\widehat{y}_{t}^{i}$ are also uncorrelated with each other, we obtain

$$
\Omega_{t}=\tau_{t} \operatorname{Var}\left(\widehat{y}_{t}^{i}\right)+\left(1-\tau_{t}\right) \operatorname{Var}\left(y_{t}^{i}-\widehat{y}_{t}^{i}\right),
$$

which is identical to what we had in the benchmark model (see condition (9)). The optimal tax rate is again bound to be a decreasing function of the signal-to-noise ratio in the income distribution, which is now given by

$$
\frac{\operatorname{Var}\left(\widehat{y}_{t}^{i}\right)}{\operatorname{Var}\left(y_{t}^{i}-\widehat{y}_{t}^{i}\right)}=\frac{\operatorname{Var}\left(\sum_{s \leq t} \alpha^{s-t}\left(1-\tau_{s}\right) \delta_{s}^{i}\right)}{\operatorname{Var}\left(\sum_{s \leq t} \alpha^{s-t} \eta_{s}^{i}\right)}
$$

and is in turn decreasing in past tax rates. 


\section{A. Alesina and G.M. Angeletos}

\subsection{Multiple steady states}

We look for fixed points such that, if $\tau_{s}=\bar{\tau}$ for all generations $s \leq t-1$, then $\tau_{t}=\bar{\tau}$ is optimal for generation $t$. To simplify we assume that $\delta_{t}^{i} \equiv \beta_{t}^{i}\left(A_{t}^{i}\right)^{2}$ and $\eta_{t}^{i}$ are i.i.d. across both $i$ and $t$, and let $\operatorname{Var}\left(\delta_{t}^{i}\right)=\sigma^{2}$ and $\operatorname{Var}\left(\eta_{t}^{i}\right)=v^{2}$ for all $i, t$. Suppose $\tau_{s}=\bar{\tau}$ for all $s \leq t-1$. The signal-to-noise ratio in generation $t$ reduces to

$$
\frac{\operatorname{Var}\left(\widehat{y}_{t}^{i}\right)}{\operatorname{Var}\left(y_{t}^{i}-\widehat{y}_{t}^{i}\right)}=\left[1-\alpha \bar{\tau}-(1-\alpha) \tau_{t}\right]^{2} \frac{\sigma^{2}}{v^{2}} \text {. }
$$

This is identical to the analogous condition (20) in the benchmark model, with only $\bar{\tau}$ now representing an average of past tax rates rather than the ex-ante anticipated contemporaneous tax rate. To abstract from the Meltzer-Richard motive for redistribution, we again assume $\delta_{m}=\mathbb{E} \delta$. Normalizing $\mathbb{E} \delta=2(1-\alpha)$, we can show that the utility of the median voter in generation $t$ reduces to

$$
u_{t}^{m}=\kappa-(1-\alpha) \tau_{t}^{2}-\gamma \Omega_{t}
$$

where $\kappa \equiv 2 \alpha(1-\bar{\tau})+(1-\alpha) . \kappa$ is historically given for generation $t$ and the second term represents the efficiency cost of taxation. Substituting $\Omega_{t}$ and maximizing with respect to $\tau_{t}$, we conclude:

Lemma 3 Let $\sigma>0$ measure the exogenous variation in genetic talent or willingness to work, $v>0$ the exogenous amount of pure luck, $\gamma \geq 0$ the desire for social justice, and $\alpha \in(0,1)$ the relative importance of intergenerational transfers in shaping the wealth distribution. Suppose that the mean and the median of the income distribution coincide and define

$$
f(\bar{\tau}) \equiv \arg \min _{\tau}\left\{\tau^{2}\left[(1-\alpha)+\left(\gamma \sigma^{2}\right)(1-\alpha \bar{\tau}-(1-\alpha) \tau)^{2}\right]+(1-\tau)^{2}\left(\gamma v^{2}\right)\right\}
$$

$f(\bar{\tau})$ represents the best-response function of a given generation against a stationary history. That is, when all previous generation have chosen $\bar{\tau}$, the optimal tax for the current generation is $f(\bar{\tau})$.

Comparing the above with Lemma 2, we see that the functional form of $f$ is identical to that in the benchmark model. Therefore, our earlier result of multiple equilibria in 


\section{FAirness And Redistribution}

the static economy directly translate to a result of multiple steady states in the dynamic economy:

Proposition 2 Suppose that the median and the mean coincide. A steady state is any

fixed point $\tau=f(\tau)$. If $\gamma=0$, the unique steady state is $\tau=0$. If instead $\gamma>0$, the tax rate is $\tau \in(0,1)$ in any steady state; the steady state is unique when $\gamma$ is sufficiently small or when $v / \sigma$ is either sufficiently small or sufficiently large; but there are two stable steady states (and one unstable) when $\gamma$ is sufficiently high and $v / \sigma$ takes moderate values.

Therefore, the example of Figure 2 can be directly reinterpreted in the context of a dynamic economy with intergenerational transfers, provided we read $\tau$ as the tax rate in some given generation and $\bar{\tau}$ as a weighted average of tax rates in all past generations. Multiple steady states again exist when the social desire for fairness is sufficiently high and the relative effect of luck takes moderate values. The two extreme intersection points, $U S$ and $E U$, correspond to the two stable steady states. Different initial conditions, or different exogenous aggregate shocks, would lead the economy to converge to either of these two steady states. $U S$ is characterized by lower taxation, lower distortions, and fairer outcomes as compared to $E U$.

Income inequality and social mobility can be higher in either steady state. Nonetheless, both inequality and mobility are mostly the effect of effort in $U S$ and mostly the effect of luck in $E U$. Moreover, mobility and inequality need not be tightly related with each other. It is quite possible that the superior steady state $(U S)$ is associated with higher inequality and yet higher social mobility. This will indeed be the case if the withinfamily cross-generation variation in talent or willingness to work is sufficiently large, since mobility will be mostly the effect of differences in effort and productivity in $U S$, whereas it will be mostly the effect of luck in $E U$.

\subsection{Equalizing opportunities for children}

In writing (27), we assumed that the society wishes to correct the cumulative effect of pure luck, but otherwise parents are fully entitled to make different transfers to their children deriving from different levels of effort. However, the society may not want to 


\section{A. Alesina and G.M. Angeletos}

keep children born by unworthy parents responsible for their parents' laziness and lack of care. There is then a conflict between what is considered fair vis-a-vis parents and what is considered fair vis-a-vis children. As a result, the society may like to make parents only partly entitled to leaving different bequests to their children, even if these difference reflect different levels of effort or parental care, so as to further equalize opportunities across children.

This possibility is easy to incorporate in our model, as follows. Let $\lambda \in(0,1)$ be the fraction of effort-driven parental bequests that children are entitled to; that is, the "fair" level of wealth is

$$
\widehat{y}_{t}^{i} \equiv A_{t}^{i} e_{t}^{i}+\lambda \sum_{s \leq t-1} \alpha^{s-t} A_{s}^{i} e_{s}^{i}
$$

$1-\lambda$ can be interpreted as a measure of the social desire for equalizing opportunities across children. The analysis goes through as before, with simply replacing $\alpha$ with $\alpha \lambda$. Assuming again that the mean and the median coincide, and normalizing $\mathbb{E} \delta=2(1-\alpha \lambda)$, we conclude that the optimal tax rate in generation $t$ when past generations have chosen $\bar{\tau}$ is given by $\tau_{t}=f(\bar{\tau})$, where

$$
f(\bar{\tau}) \equiv \arg \min _{\tau}\left\{\tau^{2}\left[(1-\alpha \lambda)+\left(\gamma \sigma^{2}\right)(1-\alpha \lambda \bar{\tau}-(1-\alpha \lambda) \tau)^{2}\right]+(1-\tau)^{2}\left(\gamma v^{2}\right)\right\}
$$

It follows that the possibility of multiple steady states remains as long as $\lambda$ is not very small. Moreover, the tax rate in any (stable) steady state is decreasing in $\lambda$; that is, redistribution increases with a higher desire to equalize opportunities across children.

Remark. We have considered only one kind of taxation and redistribution, namely income taxation coupled with lump sum transfers. Different redistributional goals given a desire for fairness could be achieved by using a mixture of different tax and redistribution instruments. For example, we can introduce an inheritance tax in addition to the income tax. A society may then consider an inheritance more or less "fair" depending on whether higher bequests are or are not due to higher ability and effort by the previous generation. Similarly, one could consider public provision of education. Our model would predict that, in an attempt to correct for the more unfair variation in children's opportunities, Europe adopts a larger government intervention in education. 


\section{FAirness AND Redistribution}

\section{Conclusion}

Many more Americans than Europeans think that the poor are lazy (or at least lazier than the rich); and many less Europeans than Americans think that market outcomes are fair. We argue that in their attempt to improve the fairness of economic outcomes, Europeans choose more redistribution and more government intervention which, in equilibrium, distorts market allocations, increases the effect of luck, and makes economic outcomes unfair. This in turn, vindicates the Europeans' beliefs and justifies their policy choices. The opposite occurs in the United States, where lower distortions imply a more fair income distribution and therefore less need for redistribution. ${ }^{24}$ These considerations help explaining why income inequality is higher in the United States than in continental Europe, and nevertheless redistributive policies are much more limited. A different way of saying this is that Americans seem much more willing than Europeans to tolerate inequality, because they (correctly) perceive income inequality as largely justified. Europeans are less willing to tolerate inequality because they perceive it (correctly) as due to luck..$^{25}$

Interestingly, the biggest differences in redistributive policies between the United States and continental Europe reside in the support for poverty per se. That is, if you are sick, old, or disabled, have dependent children, or have suffered an accident at work, you do get substantial support in the United States; but if you are merely poor, you do not get much support in the United States. ${ }^{26}$ This stylized fact is exactly what our model would predict if we allowed two kinds of "luck", observed and unobserved. Since accidents at work, sickness, and disability are mostly beyond the control of the individual and are easily observed and verified by society, the social desire to correct for their effect on income and consumption should be equally strong in the United States and in Europe. Poverty, on the other hand, can be the outcome of unobserved choice (lack of effort) rather than exogenous luck. If this is more the case in the United States than in Europe, support for

\footnotetext{
${ }^{24}$ It is worth mentioning an interesting difference with respect to Benabou and Tirole (2002). In their model it is an "illusion" that in American effort is more important than in Europe, while in our model it is a fully rational belief.

${ }^{25} \mathrm{We}$ are of course not arguing this is the only explanation of this difference. For an exhaustive discussion of additional explanations see Alesina Sacerdote and Glaeser (2001)

${ }^{26}$ See Alesina, Glaeser and Sacerdote (2001) for more detailed evidence.
} 


\section{A. Alesina and G.M. Angeletos}

poverty will indeed be lower in the United States.

We have focused on income taxation and redistribution, but the demand for fairness may have similar implications for many other policy choices as well. Consider, for example, the regulation of the labor market. Unemployment can be the outcome of either bad luck (e.g., inefficient match) or lack of effort (e.g., low job search while unemployed, or high shrinking while employed). If "everybody who is willing to work deserves a job" and the society must protect anybody who is "unjustly" laid-off, two politico-economic regimes may emerge: One in which extensive employment protection, generous unemployment benefits, low turn over, and high unemployment rates reinforce each other ("Europe"), and another in which limited regulation and efficient allocations are self-sustained as well ("United States"). Moreover, if the exogenous component of short-term unemployment is larger than that of long-term unemployment, the model would predict that American and European policies diverge with respect to long-term unemployment support but converge with respect to short-term unemployment support. This prediction is consistent with the fact that the duration of benefits is much shorter in the United States but the replacement ratio is as high as in Europe (see Table 3).

This paper has shown how the complementarity between political and economic choices that emerges in the presence of a concern for fairness can lead to multiple equilibria or multiple steady states for the same "fundamentals". More generally, however, we can think of this complementarity as an amplification and propagation mechanism for small exogenous differences. This may relate to the different historical experiences of the United States and continental European countries. In Europe, due to its history, class differences are more rooted and wealth more associated with privileges, which we can interpret as "luck" of being born in the right family. The "self-made man" is very much an American "idol"; and aversion to nobility and birth-related privileges are deeply rooted in American history, from its very beginning. At the time of the extension of the franchise in Europe more so than in the US the distribution of income was perceived as unfair because it was generated more by birth and nobility than by ability and effort; as result redistributive polices and other forms of government intervention were more aggressive. In the "land of opportunities," the perception was instead that those who were successful and wealthy had "made it" on their own, at least to a larger degree than in Europe. As a consequence, 


\section{FAIRNESS AND REDISTRIBUtion}

the Americans have chosen low redistribution, strong property protection, and limited regulation, resulting to much lower inefficiencies and a much smaller effect of "luck". ${ }^{27}$

A related issue concerns welfare and regulation reforms in Europe. Since the "European" steady state is locally stable, small "shocks", such as incremental policy reforms, may not be enough to move Europe away from the politico-economic regimes that sustains the existing system. Only large, bold, and persistent reforms may switch the politicoeconomic equilibrium to the one with low taxes, limitted regulation, and more efficient outcomes. In practice, this means that a successful welfare reform needs to convince people that market outcomes will eventually become more "fair" with lower taxes and narrower government intervention.

Finally, our paper offers just one example of how fairness may have important implications for both the normative and the positive analysis of government policies. To give another example, consider the taxation of capital income. On the one hand, fairness introduces an additional incentive for taxing capital income, to the extent that variation in investment and returns reflects the effect of "luck". On the other hand, while in a representative-agent economy it is ex post optimal to impose the maximum possible capital levy once capital is sunk, a fairness concern in a heterogeneous-agent economy limits the ex post optimal tax, to the extent that variation in investment and returns reflects the effect of talent, entrepreneurship, and past hard work. In other words, a social preference for fairness may affect both the characterization and the time inconsistency of optimal fiscal policy. We believe these are important questions for future research. ${ }^{28}$

\footnotetext{
${ }^{27}$ Different exogenous shocks may also be part of the story. For example, the two world wars have likely increased the effect of "luck" more in Europe than in the United States, while the rise of socialism has clearly increased the political demand for fairness more in Europe than in the United States.

${ }^{28}$ Recent research in the Mirrlees paradigm of optimal taxation (e.g., Golosov, Kocherlakota, and Tsyvinski, 2001; Werning, 2001) partly incorporates a concern for "fairness" in the sense of social insurance. However, the existing work assumes only ex post heterogeneity in luck; it does not allow for any ex ante heterogeneity in talent, patience, or willingness to work. Combining such ex ante and ex post heterogeneity remains an open question, just as considering the time inconsistency of Mirrlees optimal taxation.
} 


\section{Appendix: "Bad" effort, not luck}

We now consider the case in which the socially undesirable source of income inequality is due to various kinds of socially unworthy activities, or "bad effort", such as corruption, rent seeking, etc. In order to focus on this new channel, in this section we abstract from disutility of effort and cost of investment.

\section{The environment}

The agent has one unit of time or capital during the first period of life, which he can allocate in either "production" or "corruption and rent seeking." We model productive activities as in the previous section: If agent $i$ allocates $k_{i}$ in production during the first period of his life, he receives $A_{i} k_{i}$ during the second period. "Rent seeking" or "corruption", on the other hand, represent activities which do not create any new social product but merely affect the distribution of a given social product among the different agents in the economy; they are a zero-sum game. Specifically, if agent $i$ allocates a fraction $\left(1-k_{i}\right)$ of his resources to corruption and rent seeking, then he receives

$$
R_{i}=\left[z_{i}-\int_{j} z_{j}\right] G,
$$

where

$$
z_{i} \equiv\left[B_{i}\left(1-k_{i}\right)\right]^{\psi} / \psi
$$

$z_{i}$ represents the level of rent-seeking activity by agent $i$ and $\int_{j} z_{j}$ the aggregate rent seeking in the economy. $B_{i}$ measures the productivity of agent $i$ in rent seeking, his ability in negotiating with bureaucrats and lobbying with politicians, or his indifference towards the morality of his own business life. $\psi \in(0,1)$ introduces diminishing returns in rent-seeking activities; we do so only to ensure an interior solution and, for simplicity, we let $\psi=1 / 2$. Since corruption is a zero-sum game, $\int_{j} R_{i}=0$. Total income and consumption for agent $i$ are given by

$$
\begin{gathered}
y_{i}=A_{i} k_{i}+R_{i}=A_{i} k_{i}+\left[z_{i}-\mathbb{E}_{z j}\right] G, \\
c_{i}=(1-\tau) y_{i}+G .
\end{gathered}
$$




\section{FAIRness AND REDistribution}

The "fair" levels of consumption and income are:

$$
\widehat{c}_{i} \equiv \widehat{y}_{i} \equiv A_{i} k_{i}=y_{i}-R_{i}
$$

Suppose that $\widehat{y}_{i}$ and $R_{i}$ are independent; which will be true in equilibrium if and only if $A_{i}$ and $b_{i} \equiv B_{i} / A_{i}$ are independent, which we assume for simplicity. Then:

$$
\Omega=\int_{i}\left(c_{i}-\widehat{c}_{i}\right)^{2}=\tau^{2} \operatorname{Var}\left(\widehat{y}_{i}\right)+(1-\tau)^{2} \operatorname{Var}\left(R_{i}\right),
$$

By comparing the above with (15), it becomes clear that rents $R_{i}$ in the present economy play the same role that luck $\eta_{i}$ played in the benchmark economy. Finally, the government budget is

$$
G=\tau \int_{i} y_{i}=\mathbb{E} y_{i}
$$

and individual preferences are given by

$$
u_{i}=c_{i}-\gamma \Omega-(1-\alpha) \tau^{2}
$$

The last term captures any contemporaneous cost of taxation. We cut through the microfoundations only for the shake of expositional simplicity.

\section{Equilibrium allocations, corruption, and redistribution}

The FOC with respect to $k_{i}$ reduces to ${ }^{29}$

$$
1-k_{i}=B_{i}\left(\frac{G}{A_{i}}\right)^{2} .
$$

It follows that $z_{i}=2 G\left(B_{i} / A_{i}\right)$ and $\mathbb{E} z_{i}=2 G \mathbb{E}\left(B_{i} / A_{i}\right)$. Rent-seeking activity is thus increasing with the size of government. Let $b_{i} \equiv B_{i} / A_{i}$ denote the relative productivity of agent $i$ in rent seeking and, without serious loss of generality, assume that $b_{i}$ and $A_{i}$ are independent. Using (44) together with (36), (38) and (39), we infer that income from rent seeking and from "good" effort is given by

$$
R_{i}=2 G\left[b_{i}-\mathbb{E} b_{i}\right] \text { and } \widehat{y}_{i}=A_{i}-G b_{i} .
$$

\footnotetext{
${ }^{29}$ To avoid corner solutions for any agent, we assume that the parameters of the economy are such that, in any equilibrium, $B_{i}\left(G / A_{i}\right)^{2}<1$ for all $i$. This is obviously without any loss of generality.
} 


\section{A. Alesina and G.M. Angeletos}

It follows that $\mathbb{E} R_{i}=0$ (reflecting the fact that corruption is a zero-sum game) and $\mathbb{E} y_{i}=\mathbb{E} \widehat{y}_{i}=\mathbb{E} A_{i}-G \mathbb{E} b_{i}$. Normalizing $\mathbb{E} A_{i}=\mathbb{E} b_{i}=1$ and using $G=\bar{\tau} \mathbb{E} y_{i}$, we infer that aggregate output and the size of government are given by

$$
\mathbb{E} y_{i}=\frac{1}{1+\bar{\tau}} \text { and } \quad G=\frac{\bar{\tau}}{1+\bar{\tau}}
$$

where $\bar{\tau}$ again denotes the anticipated tax rate. Note that the negative dependence of aggregate output on the tax rate reflects not the usual tax distortion, as we have assumed (only for simplicity) that total resources are in fixed supply, but rather the waste of resources in rent seeking, which is proportional to the size of government.

From (45), the "variance decomposition" of income is $\operatorname{Var}\left(R_{i}\right)=4 G^{2} \operatorname{Var}\left(b_{i}\right)$ and $\operatorname{Var}\left(\widehat{y}_{i}\right)=\operatorname{Var}\left(A_{i}\right)+G^{2} \operatorname{Var}\left(b_{i}\right)$. Letting $\sigma^{2} \equiv \operatorname{Var}\left(A_{i}\right)$ and $v^{2} \equiv \operatorname{Var}\left(b_{i}\right)$, and substituting $G$ from (46), we conclude

$$
\frac{\operatorname{Var}\left(\widehat{y}_{i}\right)}{\operatorname{Var}\left(R_{i}\right)}=\frac{1}{4}+\left[1+\frac{1}{\bar{\tau}}\right]^{2} \frac{\sigma^{2}}{v^{2}} .
$$

Therefore, as the incentives to engage in corruption and rent seeking are increasing in the expected size of government, the "signal-to-noise ratio" in the income distribution is decreasing in the anticipated tax rate. Note that this relation between the "variance decomposition" of income inequality and the anticipated tax rate is isomorphic to that in the benchmark model. Now it reflects the effect of corruption rather than luck, but its implications for multiplicity are essentially the same. Two stable equilibria may again arise. If agents anticipate a high tax rate, then they allocate a large portion of their

resources in corruption rather than production, as they anticipate the private benefits of the corruption game to be large. But then most of income heterogeneity is the outcome of socially undesirable means, which in turn makes it optimal to impose a high tax rate in an attempt to redistribute from the corrupt rich to the politically disadvantaged poor. On the other hand, if agents anticipate a low tax, they allocate most of their resources in production rather than consumption. In this case, most income heterogeneity is socially desirable and the ex post optimal tax rate is small, once again vindicating agents' initial expectations.

This version of the model implies that a "benevolent" government is trying to correct some corruption that is present somewhere in the system. In a sense we are implic- 


\section{FAIRness And Redistribution}

itly viewing government activities and interaction with the public as a combination of benevolent and corrupt. A more cynical interpretation would be that some redistributive programs are introduced to placate the electorate letting corruption run wild. But a detailed modelling of corruption is beyond our scope here. ${ }^{30}$ The contemporaneous presence of corruption and redistribution may well capture the case of many developing countries, even some OECD countries (e.g., Italy, Greece), in which the welfare state is not as efficient and well-functioning as that of other European countries. These are welfare states in which redistributive programs are often mis-targeted, or favor special interests, and attempts at correcting inequities end up creating even more injustice. In other words, in the previous sections we considered a redistributive system in which redistributive flows were as well targeted as possible. In this section we have considered a case in which fiscal flows are a combination of favoritism and corruption in addition to an attempt at creating more "fair" economic outcomes.

\section{References}

[1] Alesina, A., R. Baqir, and W. Easterly (1999), "Public Goods and Ethnic Divisions" Quarterly Journal of Economics 114.

[2] Alesina, A., A. Devleeschauer, W. Easterly, W. Kurlat and R. Wacziarg (2002), "Fractionalization," unpublished.

[3] Alesina, A., E. Glaeser, and B. Sacerdote (2001), "Why Doesn't the US Have a European-style Welfare State?" Brookings Papers on Economic Activity 2:2001.

\footnotetext{
${ }^{30}$ For insightful models of corruption see Shleifer and Vishny (1993), Tirole (1993), and Banarjee (1997).
} 


\section{A. Alesina and G.M. Angeletos}

[4] Alesina A., and E. Glaeser (2003), The Welfare State in Europe and in the US: Why so different?, in preparation for Oxford University Press.

[5] Alesina, A., and E. La Ferrara (2001), "Preferences for Redistribution in the Land of Opportunities" NBER Working Paper.

[6] Angeletos, G.M., and T. Kollintzas (1997), "Rent Seeking, Corruption and Growth: A Simple Model," CEPR Discussion Paper 2464.

[7] Ball, S., C. Eckel, P. Grossman, and W. Zane (1996), "Status in Markets," unpublished.

[8] Banerjee, A. (1997), "A Theory of Misgovernance," Quarterly Journal of Economics $112,1289-1331$.

[9] Benabou, R. (2000), "Unequal societies" American Economic Review

[10] Benabou, R., and E. Ok (2001), "Social Mobility and the Demand for Redistribution: The POUM Hypothesis," Quarterly Journal of Economics 116, 447-87.

[11] Benabou, R., and J. Tirole (2002), "Belief in a Just World and Redistributive Policies," unpublished.

[12] Caselli, F., and N. Gennaioli (2002), "Dynastic Management," unpublished.

[13] Checchi, D., A. Ichino and A. Rustichini (1999), "More Equal and Less Mobile? Education Financing and Intergenerational Mobility in Italy and in the US" Journal of Public Economics 74, 351-93.

[14] Clark, J. (1998), "Fairness in Public Good Provision: An Investigation of Preferences for Equality and Proportionality," Canadian Journal of Economics 31, 708-729.

[15] Cole, H., G. Mailath, and A. Postlewaite (1992), "Social Norms, Savings Behavior, and Growth," Journal of Political Economy 100, 1092-1125.

[16] Deininger, K., and L. Squire (1996), “A New Data Set Measuring Income Inequality,” World Bank Economic Review 10, 565-91. 


\section{Fairness And Redistribution}

[17] Fehr, E., and K. Schmidt (2001), "Theories of Fairness and Reciprocity - Evidence and Economic Applications," prepared for the 8th World Congress of the Econometric Society.

[18] Fields, G., and E. Ok (1999), "Measuring Movements of Income," Econometrica 66, 455-71.

[19] Fong, C. (2002), "Social Preferences, Self-Interest and the Demand for Redistribution," Journal of Public Economics??.

[20] Glaeser, E. (2002), "A Model of Hatred," unpublished.

[21] Golosov, M., N. Kocherlakota, and A. Tsyvinski (2001), "Optimal Indirect and Capital Taxation," Review of Economic Studies, forthcoming.

[22] Gottschalk, P., and E. Spolaore (2002), "On the Evaluation of Economic Mobility," Review of Economic Studies, forthcoming.

[23] Hoffman, E., K. McCabe, K. Shachat, and V. Smith (199?), "On Expectations and the Monetary Stakes in Ultimatum Games," International Journal of Game Theory.

[24] Hoffman, E., and M. Spitzer (1985), "Entitlements, Rights, and Fairness: An Experimental Investigation of Subject's Concepts of Distributive Justice," Journal of Legal Studies 14, 259-97.

[25] La Porta, R. F. Lopez de Silanes, A. Shleifer, and R. Vishny (1999), "The Quality of Government" Journal of Law and Economics

[26] Meltzer, A., and S. Richard (1981), "A Rational Theory of the Size of Government," Journal of Political Economy 89, 914-27.

[27] Murphy, K., A. Shleifer, and R. Vishny (1991), "The Allocation of Talent: Implications for Growth," Quarterly Journal of Economics 106, 503-30.

[28] Murphy, K., A. Shleifer, and R. Vishny (1993), "Why is Rent-Seeking so Costly to Growth?" American Economic Review Papers and Proceedings 83, 409-14. 


\section{A. Alesina And G.M. Angeletos}

[29] Nickell, S. (1997), "Unemployment and Labor Market Rigidities:Europe versus North America," Journal of Economic Perspectives 11, 55-74.

[30] Nickell, S., and R. Layard (1999), "Labor Market Institutions and Economic Performance," in O. Ashenfelter and D. Card (eds) Handbook of Labor Economics, North Holland Amsterdam.

[31] Perotti, R. (1996), "Growth, Income Distribution and Democracy: What the Data Say," Journal of Economic Growth 1, 149-87.

[32] Piketty, T. (1995), "Social Mobility and Redistributive Politics," Quarterly Journal of Economics 110, 551-84.

[33] Rawls, J. (1971), The Theory of Justice, Harvard University Press.

[34] Romer, T. (1975), "Individual Welfare, Majority Voting and the Properties of a Linear Income Tax," Journal of Public Economics 7, 163-88.

[35] Shleifer, A. and R. Vishny (1993), "Corruption," Quarterly Journal of Economics 104, 599-617.

[36] Tirole J. (1993), "A Theory of Collective Reputations (with Applications to the Persistence of Corruption and to Firm Quality)," Review of Economic Studies 63, $1-22$.

[37] Werning, I. (2001), "Optimal Dynamic Taxation," unpublished. 


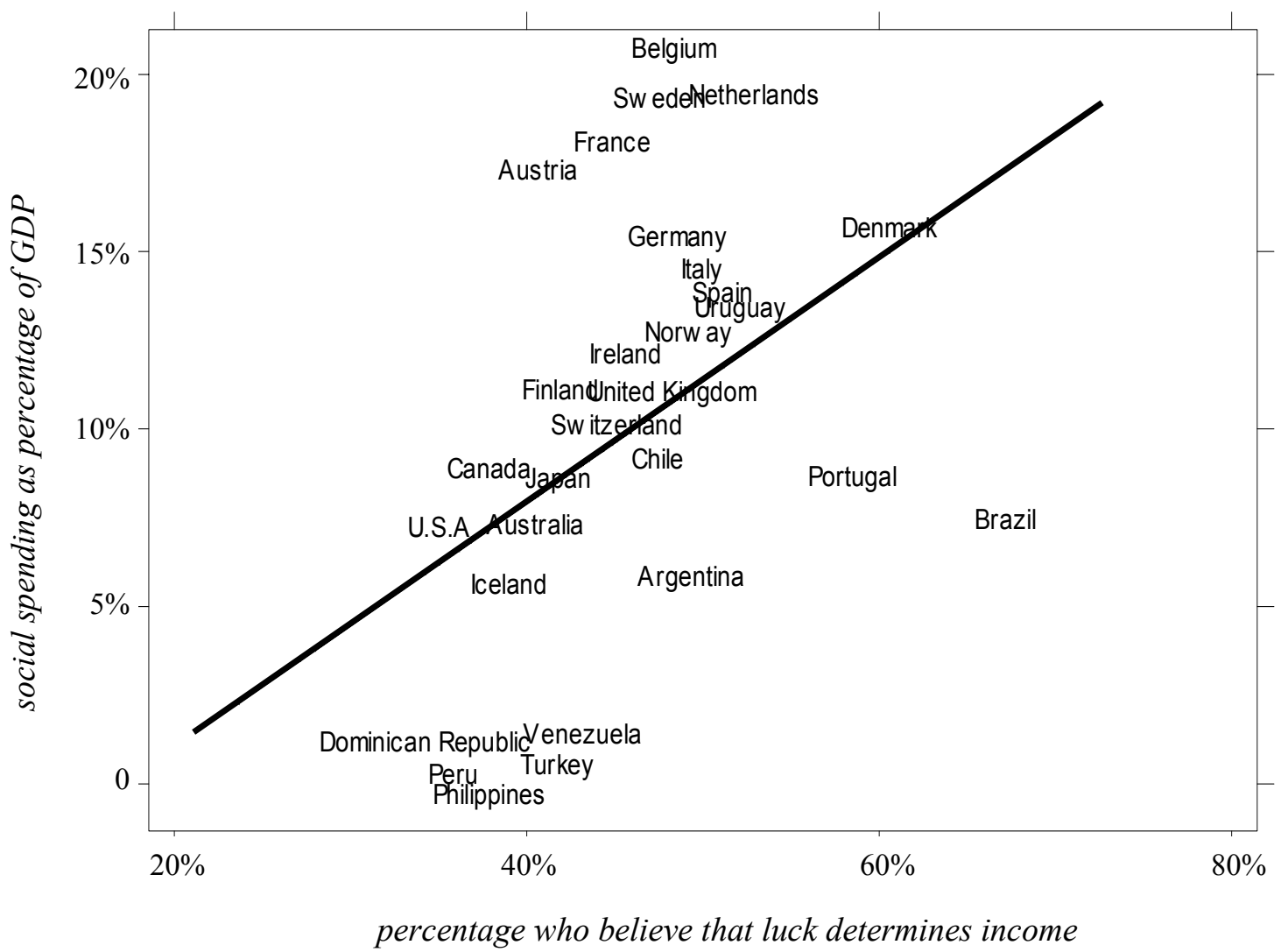

Figure 1

The above scatterplot illustrates the cross-country relation between the fraction of the population who believe that luck determines income (as measured in the World Value Survey), and the percentage of GDP allocated to social spending. 


\section{Table 1}

Composition of General Government Expenditure, 2000 (Percent of GDP)

\begin{tabular}{|c|c|c|c|c|c|c|}
\hline \multirow[b]{2}{*}{ Country } & \multirow[b]{2}{*}{ Total $^{\mathrm{a}}$} & \multicolumn{2}{|c|}{ Consumption } & \multirow[b]{2}{*}{ Subsidies } & \multirow{2}{*}{$\begin{array}{c}\text { Social } \\
\text { benefits } \\
\text { and other } \\
\text { transfers }\end{array}$} & \multirow[b]{2}{*}{$\begin{array}{c}\text { Gross } \\
\text { investment }\end{array}$} \\
\hline & & $\begin{array}{c}\text { Goods and } \\
\text { Services }\end{array}$ & $\begin{array}{l}\text { Wages and } \\
\text { salaries }\end{array}$ & & & \\
\hline United States & 29.9 & 5.3 & 9.2 & 0.4 & 10.6 & 3.3 \\
\hline Continental Europe ${ }^{\mathrm{c}}$ & 44.9 & 8.3 & 12.4 & 1.5 & 17.6 & 2.5 \\
\hline France & 48.7 & 9.7 & 13.5 & 1.3 & 19.6 & 3.2 \\
\hline Germany & 43.3 & 10.9 & 8.1 & 1.7 & 20.5 & 1.8 \\
\hline Sweden & 52.2 & 9.8 & 16.4 & 1.5 & 20.2 & 2.2 \\
\hline
\end{tabular}

Source: Authors' calculations based on data from OECD Economic Outlook Database (No. 71, Vol. 2002, Release 01), June 2002.

a. Totals also include interest payments and some categories of capital outlays.

b. Includes social security.

c. Simple average for Austria, Belgium, Denmark, Finland, France, Germany, Greece, Italy, Netherlands, Norway, Portugal, Spain and Sweden.

\section{Table 2}

Government Expenditure on Social Programs, 1998 (Percent of GDP)

\begin{tabular}{|c|c|c|c|c|c|c|}
\hline Country & Total & $\begin{array}{l}\text { Old-age, } \\
\text { disability } \\
\text { and } \\
\text { survivors }^{\mathrm{a}}\end{array}$ & Family $^{\mathrm{a}}$ & $\begin{array}{c}\text { Unemployment } \\
\text { and labor } \\
\text { market } \\
\text { programs }\end{array}$ & Health $^{\mathrm{b}}$ & Other \\
\hline United States & 14.6 & 7.0 & 0.5 & 0.4 & 5.9 & 0.9 \\
\hline Continental Europe $^{\mathrm{d}}$ & 25.5 & 12.7 & 2.3 & 2.7 & 6.1 & 1.7 \\
\hline France & 28.8 & 13.7 & 2.7 & 3.1 & 7.3 & 2.1 \\
\hline Germany & 27.3 & 12.8 & 2.7 & 2.6 & 7.8 & 1.5 \\
\hline Sweden & 31.0 & 14.0 & 3.3 & 3.9 & 6.6 & 3.2 \\
\hline
\end{tabular}

Source: Authors' calculations based on data from OECD Social Expenditure Database 1980-1998 (3 ${ }^{\text {rd }}$ Edition), 2001. a. Includes cash benefits and in kind services.

b. Includes, among other things, inpatient care, ambulatory medical services and pharmaceutical goods.

c. Includes occupational injury and disease benefits, sickness benefits, housing benefits and expenditure on other contingencies (both in cash or in kind), including benefits to low-income households.

d. Simple average for Austria, Belgium, Denmark, Finland, France, Germany, Greece, Italy, Netherlands, Norway, Portugal, Spain and Sweden. 
Table 3

Labor markets in the US and in Europe

\begin{tabular}{|l|c|c|c|c|c|}
\hline \multicolumn{1}{|c|}{ Country } & $\begin{array}{c}\text { Labor } \\
\text { standards } \\
1985-93\end{array}$ & $\begin{array}{c}\text { Employment } \\
\text { protection } \\
1990\end{array}$ & $\begin{array}{c}\text { Minimum } \\
\text { annual leave } \\
\text { (weeks) } \\
1992\end{array}$ & $\begin{array}{c}\text { Benefit } \\
\text { replacement } \\
\text { ratio (\%) } \\
1989-94\end{array}$ & $\begin{array}{c}\text { Benefit } \\
\text { duration } \\
\text { (years) } \\
1989-94\end{array}$ \\
\hline France & 6 & 14 & 5 & 57 & 3 \\
Germany & 6 & 15 & 3 & 63 & 4 \\
Sweden & 7 & 13 & 5 & 80 & 1.2 \\
UK & 0 & 7 & 0 & 38 & 4 \\
European Union (1) & 4.8 & 13.5 & 3.8 & 58.7 & 2.6 \\
US & 0 & 1 & 0 & 50 & 0.5 \\
\hline
\end{tabular}

Source: Nickell and Layard (1999) and Nickell (1997) 1. Austria, Belgium, Denmark, Finland, France, Germany, Ireland, Italy, Netherlands, Portugal, Spain, Sweden and UK. 


\section{Table 4}

Effect of belief that luck determines income on total social spending (cross-country data)

\begin{tabular}{|c|c|c|c|c|c|}
\hline \multicolumn{6}{|c|}{ Dependent variable: Total social spending } \\
\hline & 1 & 2 & 3 & 4 & 5 \\
\hline Gini coefficient & & $\begin{array}{l}-0.306^{*} \\
{[1.724]}\end{array}$ & $\begin{array}{l}-0.238^{*} \\
{[1.739]}\end{array}$ & $\begin{array}{c}-0.115 \\
{[0.613]}\end{array}$ & $\begin{array}{c}-0.041 \\
{[0.347]}\end{array}$ \\
\hline $\begin{array}{l}\text { Mean belief that luck } \\
\text { determines income }\end{array}$ & $\begin{array}{c}\mathbf{3 2 . 7 2 8}^{* * * *} \\
{[2.925]}\end{array}$ & $\begin{array}{c}32.272 * * * \\
{[3.064]}\end{array}$ & $\begin{array}{c}\mathbf{3 6 . 4 3 0}^{*} * * * \\
{[3.305]}\end{array}$ & $\begin{array}{c}31.782 * * \\
{[2.521]}\end{array}$ & $\begin{array}{l}\mathbf{1 3 . 7 5 8} \\
{[1.345]}\end{array}$ \\
\hline Latin America & $\begin{array}{c}-6.950 * * * \\
{[3.887]}\end{array}$ & $\begin{array}{l}-4.323 \\
{[1.472]}\end{array}$ & $\begin{array}{c}-2.992 \\
{[0.941]}\end{array}$ & $\begin{array}{c}0.413 \\
{[0.098]}\end{array}$ & $\begin{array}{c}2.344 \\
{[0.832]}\end{array}$ \\
\hline Asia & $\begin{array}{c}-9.244 * * * \\
{[6.684]}\end{array}$ & $\begin{array}{c}-6.075^{* *} \\
{[2.153]}\end{array}$ & $\begin{array}{l}-0.808 \\
{[0.142]}\end{array}$ & $\begin{array}{c}4.657 \\
{[0.618]}\end{array}$ & $\begin{array}{c}0.774 \\
{[0.314]}\end{array}$ \\
\hline GDP pc & & & $\begin{array}{c}3.148 \\
{[1.348]}\end{array}$ & $\begin{array}{c}4.754 \\
{[1.548]}\end{array}$ & $\begin{array}{l}-1.202 \\
{[0.742]}\end{array}$ \\
\hline Population above 65 & & & & & $\begin{array}{c}1.430^{* * *} \\
{[3.833]}\end{array}$ \\
\hline Popu b/w 15 and 64 & & & & & $\begin{array}{c}0.079 \\
{[0.337]}\end{array}$ \\
\hline Majoritarian & & & $\begin{array}{c}0.493 \\
{[0.184]}\end{array}$ & $\begin{array}{c}0.031 \\
{[0.011]}\end{array}$ & \\
\hline Presidential & & & & $\begin{array}{c}-4.24 \\
{[1.392]}\end{array}$ & \\
\hline constant & $\begin{array}{c}-3.088 \\
{[0.590]}\end{array}$ & $\begin{array}{c}7.907 \\
{[1.396]}\end{array}$ & $\begin{array}{l}-25.207 \\
{[1.152]}\end{array}$ & $\begin{array}{l}-41.401 \\
{[1.425]}\end{array}$ & $\begin{array}{c}-3.937 \\
{[0.215]}\end{array}$ \\
\hline Observations & 29 & 26 & 26 & 26 & 26 \\
\hline Adjusted R-squared & 0.431 & 0.494 & 0.495 & 0.496 & 0.7 \\
\hline
\end{tabular}

Robust $t$ statistics in brackets

* significant at $10 \%$;* significant at $5 \%$; *** significant at $1 \%$ 


\section{Table 5}

The effect of mean belief that luck determines income on social spending, excluding old age, disability and survivors' benefits (cross-country data)

\begin{tabular}{|l|c|c|c|}
\hline \multicolumn{3}{|c|}{ Dependent variable: Social spending excluding old age, disability and survivors' benenefits } \\
& $\mathbf{1}$ & $\mathbf{2}$ & $\mathbf{3}$ \\
\hline Gini coefficient & -0.232 & -0.014 & $-0.242^{*}$ \\
Mean belief that luck & {$[1.617]$} & {$[0.129]$} & {$[1.824]$} \\
determines income & $\mathbf{2 9 . 8 1 7 ^ { * * }}$ & $\mathbf{2 2 . 0 8 5 ^ { * }}$ & $\mathbf{2 7 . 6 8 6 ^ { * * }}$ \\
GDP pc & {$[2.552]$} & {$[2.026]$} & {$[2.317]$} \\
& $7.156^{* * *}$ & $10.162^{* * *}$ & $7.005^{* *}$ \\
Population above 65 & {$[3.868]$} & {$[5.893]$} & {$[2.811]$} \\
& & & $0.529^{*}$ \\
Population 15-64 & & & {$[1.857]$} \\
& & & $-0.631^{*}$ \\
Majoritarian & & & {$[1.832]$} \\
& & -1.85 & \\
Presidential & {$[0.895$} & {$[1.143]$} & \\
& & $-6.924 * * *$ & \\
Constant & & {$[3.536]$} & -22.528 \\
\hline Observations & 20 & $-89.823^{* * *}$ & 20 \\
Adjusted R-squared & 0.511 & {$[5.394]$} & 0.609 \\
\hline
\end{tabular}

Robust $\mathrm{t}$ statistics in brackets

$*$ significant at $10 \%$; ** significant at $5 \%$; *** significant at $1 \%$ 


\section{Table 6}

The effect of belief that luck determines income on individual political orientation (individual data)

\begin{tabular}{|c|c|c|c|}
\hline \multicolumn{4}{|c|}{ Dependent variable: Being left on the political spectrum } \\
\hline & 1 & 2 & 3 \\
\hline US resident & $\begin{array}{c}-0.125 \\
(12.14)^{* *}\end{array}$ & $\begin{array}{c}-0.096 \\
(3.31)^{* *}\end{array}$ & $\begin{array}{l}-0.051 \\
(1.37)\end{array}$ \\
\hline Income & $\begin{array}{c}-0.01 \\
(7.20)^{* *}\end{array}$ & $\begin{array}{c}-0.009 \\
(3.31)^{* *}\end{array}$ & $\begin{array}{c}-0.009 \\
(3.88) * *\end{array}$ \\
\hline Years of education & $\begin{array}{c}-0.004 \\
(3.79)^{* *}\end{array}$ & $\begin{array}{l}-0.002 \\
(0.74)\end{array}$ & $\begin{array}{l}0.000 \\
(0.07)\end{array}$ \\
\hline City population & $\begin{array}{c}0.01 \\
(7.43)^{* *}\end{array}$ & $\begin{array}{c}0.01 \\
(4.29)^{* *}\end{array}$ & $\begin{array}{c}0.009 \\
(4.40)^{* *}\end{array}$ \\
\hline White & $\begin{array}{l}0.036 \\
(4.83)\end{array}$ & $\begin{array}{c}0.051 \\
(3.13)^{* *}\end{array}$ & $\begin{array}{c}0.033 \\
(2.11)^{*}\end{array}$ \\
\hline Married & $\begin{array}{c}-0.026 \\
(3.22)^{* *}\end{array}$ & $\begin{array}{c}-0.03 \\
(2.97)^{* *}\end{array}$ & $\begin{array}{c}-0.032 \\
(3.11)^{* *}\end{array}$ \\
\hline No. of children & $\begin{array}{c}-0.009 \\
(3.63)^{* *}\end{array}$ & $\begin{array}{c}-0.01 \\
(3.09)^{* *}\end{array}$ & $\begin{array}{c}-0.013 \\
(3.59) * *\end{array}$ \\
\hline Female & $\begin{array}{c}-0.044 \\
(6.93)^{* *}\end{array}$ & $\begin{array}{c}-0.043 \\
(3.43)^{* *}\end{array}$ & $\begin{array}{c}-0.039 \\
(3.39)^{* *}\end{array}$ \\
\hline $\begin{array}{l}\text { Individual belief that luck } \\
\text { determines income }\end{array}$ & & $\begin{array}{c}\mathbf{0 . 5 4 1} \\
(3.69)^{* *}\end{array}$ & $\begin{array}{c}\mathbf{0 . 6 0 7} \\
(3.78)^{* *}\end{array}$ \\
\hline Age group 18-24 & $\begin{array}{c}0.11 \\
(6.19)^{* *}\end{array}$ & $\begin{array}{c}0.078 \\
(3.41)^{* *}\end{array}$ & $\begin{array}{c}0.007 \\
(3.11)^{* *}\end{array}$ \\
\hline Age group 25-34 & $\begin{array}{c}0.131 \\
(11.73)^{* *}\end{array}$ & $\begin{array}{c}0.116 \\
(7.23)^{* *}\end{array}$ & $\begin{array}{c}0.114 \\
(7.00)^{* *}\end{array}$ \\
\hline Age group 35-44 & $\begin{array}{c}0.126 \\
(12.03)^{* *}\end{array}$ & $\begin{array}{c}0.117 \\
(8.96)^{* *}\end{array}$ & $\begin{array}{c}0.12 \\
(9.27)^{* *}\end{array}$ \\
\hline Age group $45-54$ & $\begin{array}{c}0.085 \\
(7.98)^{* *}\end{array}$ & $\begin{array}{c}0.081 \\
(6.37)^{* *}\end{array}$ & $\begin{array}{c}0.08 \\
(6.03)^{* *}\end{array}$ \\
\hline Age group 55-64 & $\begin{array}{c}0.039 \\
(3.55)^{* *}\end{array}$ & $\begin{array}{c}0.038 \\
(3.25)^{* *}\end{array}$ & $\begin{array}{c}0.037 \\
(3.00)^{* *}\end{array}$ \\
\hline Constant & $\begin{array}{c}0.347 \\
(16.15)^{* *}\end{array}$ & $\begin{array}{l}0.045 \\
(0.62)\end{array}$ & $\begin{array}{l}0.218 \\
(1.64)\end{array}$ \\
\hline Observations & 20269 & 16478 & 14998 \\
\hline R-squared & 0.03 & 0.03 & 0.04 \\
\hline
\end{tabular}

Absolute value of $t$ statistics in parentheses

* significant at $5 \%$; * significant at $1 \%$ 


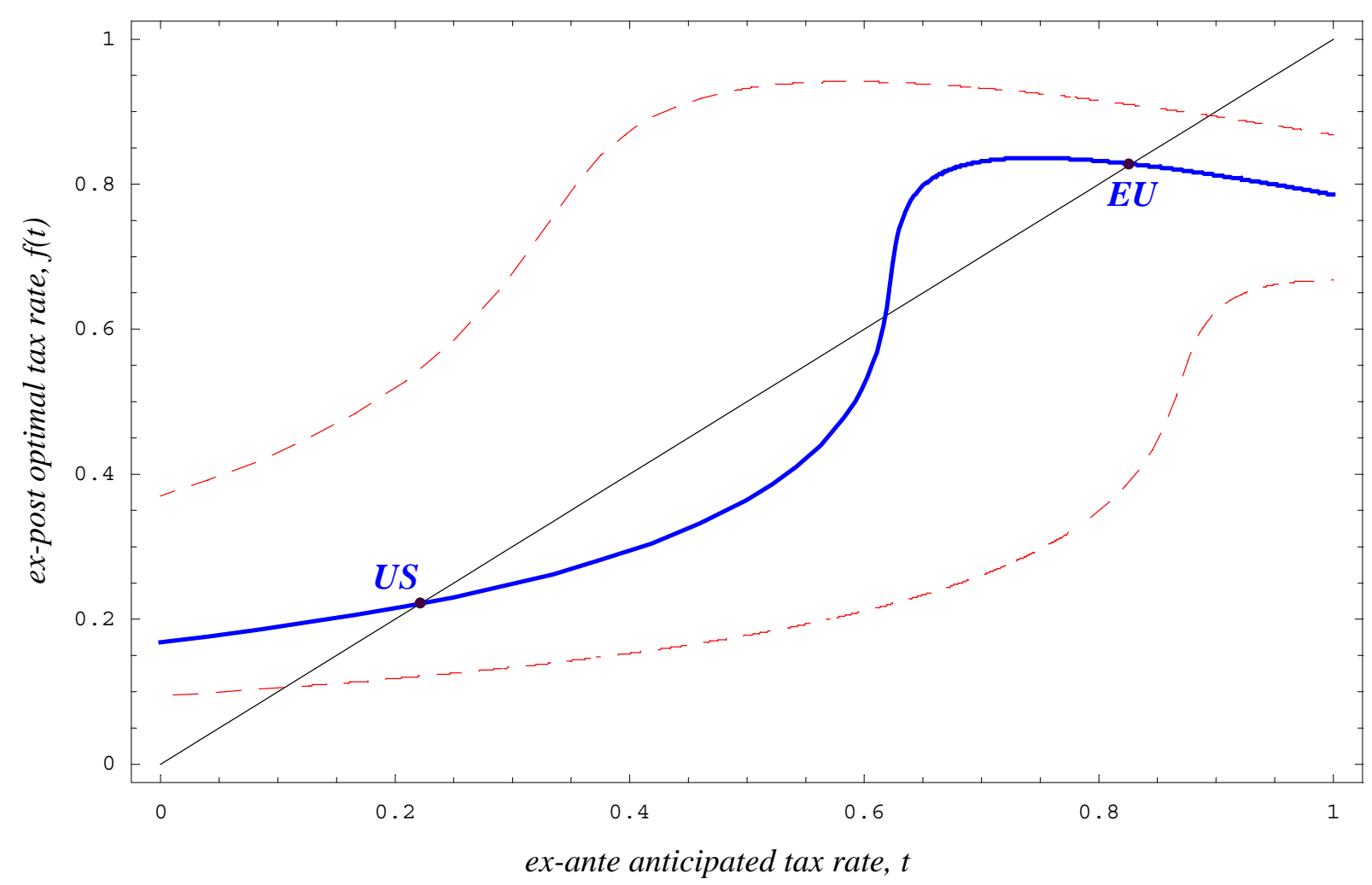

Figure 2

The above figure depicts the relation between the tax rate that agents anticipate ex ante, and the tax rate that the society (median voter) finds optimal ex post. The solid curve represents an economy where the exogenous noise (luck) in the income distribution is moderate as compared to the exogenous heterogeneity in talent, patience, or willingness to work. A politico-economic equilibrium corresponds to any intersection of this curve with the 45-degree line. In this case, there are two stable equilibria, one with low injustice and low taxation (US), and one with high injustice and high taxation (EU). The lower dashed line, on the other hand, represents an economy where the noise in the income distribution is very small, the social desire for fairness is very week, or the cost of taxation is very high. In this economy, only the low-tax regime survives. Finally, the upper dashed line represents an economy where both the desire and the ability to redistribute are high, in which case only the high-tax regime survives. 